\title{
The climate change mitigation effects of daily active travel in cities
}

Christian Brand ${ }^{\text {a,b,* }}$, Evi Dons ${ }^{\text {c,d }}$, Esther Anaya-Boig ${ }^{\text {e }}$, Ione Avila-Palencia ${ }^{\text {f,g }}$, Anna Clark ${ }^{\mathrm{h}}$, Audrey de Nazelle ${ }^{\mathrm{e}}$, Mireia Gascon ${ }^{\mathrm{f}, \mathrm{i}, \mathrm{j}}$, Mailin Gaupp-Berghausen ${ }^{\mathrm{k}}$, Regine Gerike $^{1}$, Thomas Götschi ${ }^{\mathrm{m}}$, Francesco Iacorossi ${ }^{\mathrm{n}}$, Sonja Kahlmeier ${ }^{\mathrm{o}, \mathrm{p}}$, Michelle Laeremans $^{c, t}$, Mark J Nieuwenhuijsen ${ }^{\mathrm{f}, \mathrm{i}, \mathrm{j}}$, Juan Pablo Orjuela ${ }^{\mathrm{a}, \mathrm{e}}$, Francesca Racioppi ${ }^{\mathrm{q}}$, Elisabeth Raser ${ }^{\mathrm{u}}$, David Rojas-Rueda ${ }^{\mathrm{f}, \mathrm{s}}$, Arnout Standaert ${ }^{\mathrm{c}}$, Erik Stigell $^{\mathrm{h}}$, Simona Sulikova ${ }^{\mathrm{a}}$, Sandra Wegener ${ }^{\mathrm{r}}$, Luc Int Panis ${ }^{\mathrm{c}, \mathrm{d}, \mathrm{t}}$

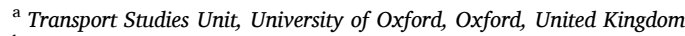

${ }^{\mathrm{b}}$ Centre for Research on Energy Demand Solutions, University of Oxford, Oxford, United Kingdom

${ }^{\mathrm{c}}$ Flemish Institute for Technological Research (VITO), Mol, Belgium

${ }^{\mathrm{d}}$ Centre for Environmental Sciences, Hasselt University, Diepenbeek, Belgium

e Centre for Environmental Policy, Imperial College London, London, United Kingdom

${ }^{\mathrm{f}}$ ISGlobal, Barcelona, Spain

${ }^{\mathrm{g}}$ Urban Health Collaborative, Dornsife School of Public Health, Drexel University, Philadelphia, USA

${ }^{\mathrm{h}}$ Trivector Traffic, Stockholm, Sweden

${ }^{\mathrm{i}}$ Universitat Pompeu Fabra (UPF), Barcelona, Spain

${ }^{\mathrm{j}}$ CIBER Epidemiología y Salud Pública (CIBERESP), Spain

${ }^{\mathrm{k}}$ Austrian Institute for Regional Studies (ÖIR), Vienna, Austria

${ }^{1}$ Dresden University of Technology, Chair of Integrated Transport Planning and Traffic Engineering, Dresden, Germany

${ }^{\mathrm{m}}$ University of Oregon, School of Planning, Public Policy and Management, Eugene, OR

${ }^{\mathrm{n}}$ Agenzia Roma Servizi per la Mobilita' Srl, Rome, Italy

${ }^{\circ}$ Department of Health, Swiss Distance University of Applied Science (FFHS), Brig, Switzerland

${ }^{\mathrm{p}}$ Biostatistics and Prevention Institute (EBPI), Epidemiology, University of Zurich, Zurich, Switzerland

${ }^{\mathrm{q}}$ World Health Organization Regional Office for Europe, European Centre for Environment and Health, Bonn, Germany

${ }^{\mathrm{r}}$ University of Natural Resources and Life Sciences Vienna, Institute for Transport Studies, Vienna, Austria

${ }^{\mathrm{s}}$ Department of Environmental and Radiological Health Sciences, Colorado State University, Fort Collins, CO, USA

${ }^{\mathrm{t}}$ Transportation Research Institute (IMOB), Hasselt University, Diepenbeek, Belgium

" Austrian Federal Railways (ÖBB), Vienna, Austria

\section{A R T I C L E I N F O}

\section{Keywords:}

$\mathrm{CO}_{2}$ emissions

Active mobility

Walking

Cycling

Climate change mitigation

Sustainable urban transport

\begin{abstract}
A B S T R A C T
Active travel (walking or cycling for transport) is considered the most sustainable form of personal transport. Yet its net effects on mobility-related $\mathrm{CO}_{2}$ emissions are complex and underresearched. Here we collected travel activity data in seven European cities and derived life cycle $\mathrm{CO}_{2}$ emissions across modes and purposes. Daily mobility-related life cycle $\mathrm{CO}_{2}$ emissions were $3.2 \mathrm{kgCO}_{2}$ per person, with car travel contributing $70 \%$ and cycling $1 \%$. Cyclists had $84 \%$ lower life cycle $\mathrm{CO}_{2}$ emissions than non-cyclists. Life cycle $\mathrm{CO}_{2}$ emissions decreased by $-14 \%$ per additional cycling trip and decreased by $-62 \%$ for each avoided car trip. An average person who 'shifted travel modes' from car to bike decreased life cycle $\mathrm{CO}_{2}$ emissions by $3.2 \mathrm{kgCO}_{2} /$ day.
\end{abstract}

\footnotetext{
* Corresponding author at: Transport Studies Unit, University of Oxford, South Parks Road, Oxford OX1 3QY, United Kingdom.

E-mail address: christian.brand@ouce.ox.ac.uk (C. Brand).
} 
Promoting active travel should be a cornerstone of strategies to meet net zero carbon targets, particularly in urban areas, while also improving public health and quality of urban life.

\section{Introduction}

Transport has been one of the most challenging sectors for reducing its significant impacts of fossil energy use and associated greenhouse gas (GHG) emissions since the 1990s (Sims et al., 2014). In Europe, GHG emissions decreased in the majority of sectors between 1990 and 2017, with the exception of transport (EEA, 2019). Modal shifts away from carbon-intensive to low-carbon modes of travel hold considerable potential to mitigate carbon emissions (Cuenot et al., 2012). Given the urgency of moving to a 'net zero' carbon emissions economy, there is growing consensus that technological substitution via electrification will not be sufficient or fast enough to transform the transport system (Creutzig et al., 2018; IPCC, 2018). Beyond a net reduction in travel demand, one of the more promising ways to reduce transport carbon dioxide $\left(\mathrm{CO}_{2}\right)$ emissions ${ }^{1}$ is to promote and invest in 'active travel' (that is, walking, cycling, or e-biking for transport) while 'demoting' motorized modes that rely on fossil energy sources (Bearman and Singleton, 2014; Castro et al., 2019; de Nazelle et al., 2010; ECF, 2011; Frank et al., 2010; Goodman et al., 2012; Keall et al., 2018; Neves and Brand, 2019; Quarmby et al., 2019; Sælensminde, 2004; Scheepers et al., 2014; Tainio et al., 2017; Woodcock et al., 2018). This could reduce $\mathrm{CO}_{2}$ emissions from road transport more quickly than technological measures alone, particularly in urban areas (Beckx et al., 2013; Creutzig et al., 2018; Graham-Rowe et al., 2011; Neves and Brand, 2019). This may become even more relevant considering the vast economic effects of the COVID-19 pandemic, which may result in reduced capacities of individuals and organizations to renew the rolling stock of vehicles in the short and medium period, and of governments to provide incentives to fleet renewal.

So how much carbon can be saved - overall - by active travel? The complex relationships between carbon emissions and transport in general have been investigated for many years. From previous research we know that mobility-related carbon emissions are determined by transport mode choice and usage, which in turn are influenced by journey purpose (e.g. commuting, visiting friends and family, shopping), individual and household characteristics (e.g. location, socio-economic status, car ownership, type of car, bike access, perceptions related to the safety, convenience and social status associated with active travel), land use and built environment factors (which impact journey lengths and trip rates), accessibility to public transport, jobs and services, and meteorological conditions (Adams, 2010; Alvanides, 2014; Anable and Brand, 2019; Bearman and Singleton, 2014; Brand and Preston, 2010; Buehler, 2011; Cameron et al., 2003; Carlsson-Kanyama and Linden, 1999; Javaid et al., 2020; Ko et al., 2011; Nicolas and David, 2009; Stead, 1999; Timmermans et al., 2003).

However, to answer the above question on the role of active travel in this, it is important to understand why, where, when and how far people travel by active and motorized modes of travel. Many studies do not dig that deep and across different contexts, thus presenting us with a number of shortcomings. First, many studies are based on analyses of the potential for emissions mitigation by developing hypothetical mitigation scenarios (see e.g. Goodman et al., 2019; Lovelace et al., 2011; Tainio et al., 2017; Woodcock et al., 2018; Yang et al., 2018). While this is useful in its own right, it sometimes lacks the empirical evidence needed to underpin the hypotheses. Second, the majority of studies are focusing on a single city, region or country (Brand et al., 2014; Neves and Brand, 2019), thus limiting the potential for generalizability and transferability to other populations and contexts. Third, the majority of active travel studies tackle carbon emissions from end-use only (Goodman et al., 2019), thus omitting the full life cycle impacts of (active and motorized) travel. It is worth noting that, on a life cycle emissions basis, cycling cannot be considered a 'zero-carbon emissions' mode of transport. The manufacture, maintenance and disposal of bikes (plus batteries and motors in the case of e-bikes), as well as potential dietary changes due to more physical activity, produce carbon emissions further up- or downstream. Overall, however, life cycle emissions from cycling can be more than ten times lower per passenger-km travelled than those from passenger cars (ECF, 2011).

To address these shortcomings and better understand the carbon-reduction impacts of active travel, it is thus important to assess the key determinants of travel carbon emissions across a wide range of contexts and include a detailed, comparative analysis of the distribution and composition of emissions by transport mode (e.g. bike, car, van, public transport, e-bike) and emissions source (e.g. vehicle use, energy supply, vehicle manufacturing). For most journey purposes active travel covers short to medium trips - typically 2 $\mathrm{km}$ for walking, $5 \mathrm{~km}$ for cycling and $10 \mathrm{~km}$ for e-biking (Castro et al., 2019). Typically, the majority of trips in this range is made by car (Beckx et al., 2013; JRC, 2013; Keall et al., 2018; Neves and Brand, 2019; U.S. Department of Transportation, 2017), with short trips contributing disproportionately to emissions because of 'cold starts', especially in colder climates (Beckx et al., 2010; de Nazelle et al., 2010). On the other hand, these short trips, which represent the majority of trips undertaken by car within cities, would be amenable to at least a partial modal shift towards active travel (Beckx et al., 2013; Carse et al., 2013; de Nazelle et al., 2010; Goodman et al., 2014; Keall et al., 2018; Neves and Brand, 2019; Vagane, 2007). To investigate these issues, we included seven European cities with different travel activity patterns, transport mode shares, infrastructure provisions, climates, mobility cultures and socio-economic makeups. To the best of our knowledge no international multicenter study on the associations of daily active and motorized travel and carbon emissions has been reported.

\footnotetext{
${ }^{1}$ For transport, $\mathrm{CO}_{2}$ is by far the most important greenhouse gas, comprising approximately $99 \%$ of direct greenhouse gas emissions. Surface transport is still dominated by vehicles with internal combustion engines running on petrol (gasoline) and diesel fuels. These propulsion systems emit relatively small amounts of the non- $\mathrm{CO}_{2}$ greenhouse gases methane $\left(\mathrm{CH}_{4}\right)$ and nitrous oxide $\left(\mathrm{N}_{2} \mathrm{O}\right)$, adding approximately $1 \%$ to total greenhouse gas emissions over and above $\mathrm{CO}_{2}$.
} 
Table 1

Mean $\mathrm{CO}_{2}$ emissions per passenger-km by city, emissions category and transport mode (showing 2014-2016 averages to match study period).

\begin{tabular}{|c|c|c|c|c|c|c|c|c|c|c|c|c|c|c|c|c|}
\hline & \multicolumn{4}{|c|}{ Operational } & \multicolumn{6}{|c|}{ Energy/fuel supply } & \multicolumn{6}{|c|}{ Vehicle supply } \\
\hline & \multirow{2}{*}{\multicolumn{2}{|c|}{$\begin{array}{l}\text { Car, van or motorcycle * } \\
\mathrm{gCO}_{2} / \mathrm{pkm}\end{array}$}} & \multirow{2}{*}{\multicolumn{2}{|c|}{$\begin{array}{l}\text { Public transport }^{\dagger} \\
\mathrm{gCO}_{2} / \mathrm{pkm}^{\prime}\end{array}$}} & \multirow{2}{*}{\multicolumn{2}{|c|}{$\begin{array}{l}\text { Car, van, motorcycle * } \\
\mathrm{gCO}_{2} / \mathrm{pkm}\end{array}$}} & \multirow{2}{*}{\multicolumn{2}{|c|}{$\begin{array}{l}\text { Public transport }^{\dagger} \\
\mathrm{gCO}_{2} / \mathrm{pkm}\end{array}$}} & \multirow{2}{*}{\multicolumn{2}{|c|}{$\frac{\text { Bicycle, e-bike }^{\#}}{\mathrm{gCO}_{2} / \mathrm{pkm}}$}} & \multirow{2}{*}{\multicolumn{2}{|c|}{$\begin{array}{l}\text { Car, van, motorcycle * } \\
\mathrm{gCO}_{2} / \mathrm{pkm}\end{array}$}} & \multirow{2}{*}{\multicolumn{2}{|c|}{$\frac{\text { Public transport }^{\dagger}}{\mathrm{gCO}_{2} / \mathrm{pkm}}$}} & \multirow{2}{*}{\multicolumn{2}{|c|}{$\begin{array}{l}\text { Bicycle, e-bike } \\
\mathrm{gCO}_{2} / \mathrm{pkm}\end{array}$}} \\
\hline & & & & & & & & & & & & & & & & \\
\hline & mean & SD & mean & SD & mean & SD & mean & SD & mean & SD & mean & SD & mean & SD & mean & SD \\
\hline Antwerp & 141.5 & 38.6 & 14.5 & 0.1 & 27.2 & 5.6 & 20.9 & 0.5 & 0.111 & 0.003 & 12.9 & 1.9 & 2.9 & 0.0 & 5.1 & 0.0 \\
\hline Barcelona & 142.2 & 45.8 & 17.2 & 0.1 & 27.5 & 7.2 & 30.5 & 0.6 & 0.171 & 0.004 & 10.6 & 1.6 & 3.0 & 0.0 & 5.1 & 0.0 \\
\hline London & 165.6 & 46.7 & 52.0 & 0.3 & 30.4 & 6.8 & 43.5 & 0.6 & 0.236 & 0.004 & 12.9 & 1.9 & 3.6 & 0.0 & 5.1 & 0.0 \\
\hline Oerebro & 153.3 & 46.8 & 68.8 & 0.3 & 27.5 & 6.1 & 16.7 & 0.1 & 0.011 & 0.000 & 13.2 & 2.1 & 4.2 & 0.0 & 5.1 & 0.0 \\
\hline Rome & 144.5 & 37.5 & 36.4 & 0.2 & 27.7 & 6.0 & 33.9 & 0.6 & 0.200 & 0.004 & 11.5 & 1.8 & 3.1 & 0.0 & 5.1 & 0.0 \\
\hline Vienna & 156.1 & 45.2 & 24.7 & 0.1 & 29.4 & 6.6 & 16.6 & 0.2 & 0.087 & 0.002 & 13.3 & 2.0 & 2.8 & 0.0 & 5.1 & 0.0 \\
\hline Zurich & 143.6 & 45.7 & 43.4 & 0.2 & 26.8 & 6.2 & 9.8 & 0.1 & 0.002 & 0.000 & 12.5 & 1.8 & 3.4 & 0.0 & 5.1 & 0.0 \\
\hline
\end{tabular}

Sources: hot and cold emissions factor coefficients (EEA, 2012; EMEP/EEA, 2016); vehicle fleets (ACEA/ANFAC, 2014; DEFRA/DECC, 2016; DfT, 2015; SMMT, 2016).

" This incorporates different journey speeds, vehicle occupancy rates by trip purpose, national fuel shares of the vehicle fleet, and cold start emissions. A $22 \%$ uplift was applied to account for 'real world'

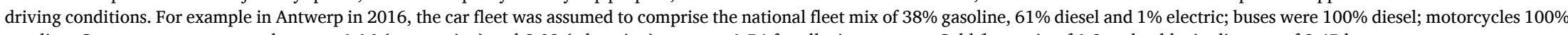
gasoline. Car occupancy rate was between 1.16 (commuting) and 2.02 (education), average 1.54 for all trip purposes. Cold/hot ratio of 1.3 and cold trip distance of 3.45 km.

†perational emissions are for bus using average occupancy rates. Energy/fuel supply assume a bus/rail share based on EPOMM Modal Split Tool. (http://www.epomm.eu/tems/). For example, Antwerp bus/rail share was 37.5\% in 2016 .

\# The observed e-bike share was 4.5\%; therefore, average emissions include $4.5 \%$ e-bike, $95.5 \%$ normal bike. 
This study also addresses a number of practical needs. First, there is a lack of standardized definitions and measurements (selfreported or measured) to identify groups within a population who use a 'main' mode of transport (e.g. based on distance, duration or frequency over a given time period), or who may be classified as 'frequent cyclists', 'occasional walkers' - or simply 'cycling' (yes/no). These should be split as much as possible as there may be different effects on overall $\mathrm{CO}_{2}$ emissions. Second, given the dominance of travel by car and public transport, active modes must be included to the extent possible by oversampling people using these modes. And finally, instead of focusing on the commute journey only, as with many studies that rely on Census data, trips for a wider range of journey purposes should be considered.

This paper aims to investigate to what extent active travel is associated with lower carbon emissions from daily travel activity. Using primary data collected in a large European multicenter study of transport, environment and health, the paper first describes how total life cycle $\mathrm{CO}_{2}$ emissions from daily travel activity were derived at the individual and population levels, considering urban transport modes, trip stages, trip purposes and emissions categories. The core analysis then identifies the main determinants and models the effects of mode choice and usage on life cycle carbon emissions. Further analysis identifies and compares differences in life cycle carbon emissions between 'groups of transport users', including by 'main' mode of transport and different categories of cycling frequency. By doing so, the paper provides a detailed and nuanced assessment of the benefits of active travel in reducing total life cycle carbon emissions in cities.

\section{Materials \& methods}

\subsection{Study design and population}

This study used longitudinal data from the 'Physical Activity through Sustainable Transport Approaches' (PASTA) project (Dons et al., 2015; Gerike et al., 2016). The analytical framework of PASTA distinguished hierarchical levels for various factors (i.e. city, individual, and trips), and four main domains that influence mobility behavior, namely factors relating to transport mode choice and use, socio-demographic factors, socio-geographical factors, and socio-psychological factors (Dons et al., 2015; Götschi et al., 2017). Seven European cities (Antwerp, Barcelona, London, Orebro, Rome, Vienna, and Zurich) were selected to provide a good representativeness of urban environments in terms of size, built environment, transport provision, modal split and ambition to increase levels of active travel (Raser et al., 2018). To ensure sufficiently large sample sizes for different transport modes, users of less common transport modes such as cycling were oversampled (Raser et al., 2018). Participants were recruited opportunistically on a rolling basis following a standardized guidance for all cities and also some city-specific approaches. A comprehensive user engagement strategy was applied to minimize attrition over the two-year timeframe. Further details on the recruitment strategy are given elsewhere (Gaupp-Berghausen et al., 2019).

A total of 10,722 participants entered the study on a rolling basis between November 2014 and November 2016 by completing a baseline questionnaire (BLQ). Participants provided detailed information on general travel behavior, daily travel activity, geolocations (home, work, education), vehicle ownership (private motorized, bicycle, etc.), public transport accessibility and socio-demographic characteristics. Follow-up questionnaires were distributed every two weeks: every third of these follow-up questionnaires also included a one-day travel diary, henceforth labelled a 'long follow-up' (long FUQ) (Dons et al., 2015). All valid travel diaries were included in the analyses, with participants providing multiple diary data at different time points. Using longitudinal data of repeated measurements of daily travel activity has been shown to improve measurement of 'typical' travel behavior (Branion-Calles et al., 2019). Participants had to be 18 years of age (16 years in Zurich) or older, and had to give informed consent at registration. Data handling and ethical considerations regarding confidentiality and privacy of the information collected were reported in the study protocol (Dons et al., 2015). Table S2 in the Supplementary Information provides an excerpt of the PASTA BLQ, including travel diary data.

\subsection{Exposure: transport mode choice and use}

The primary exposure variables were daily trip frequencies obtained from the travel diaries, for each of the main modes: walking; cycling; e-biking; motorcycle or moped; public transport; and car or van. The most common metric used by local and national administrations across the world is mode share (or split) by trip frequency, not by distance (EPOMM, 2020; U.S. Department of Transportation, 2017); hence the results of the primary exposure analysis may be used to estimate life cycle $\mathrm{CO}_{2}$ emissions directly from trip mode share data. Due to low counts of e-biking and motorcycle trips, e-biking was merged with cycling, with indirect emissions derived from observed bike/e-bike shares (see also footnote of Table 1). Also, motorcycle was merged with car as reported $\mathrm{CO}_{2}$ emission rates for motorcycles are comparable to cars on a per passenger-km basis (BEIS, 2019). Participants provided information on each trip made on the previous day, including start time, location of origin, transport mode, trip purpose, location of destination, end time and duration (Supplementary Table S2). The diary was based on the established KONTIV-Design (Brög et al., 2009; Socialdata, 2009), with some adaptations for online use. 5623 participants provided a valid travel diary in either the BLQ or the long FUQ; out of those 3836 participants completed valid baseline surveys and travel diaries. In the travel diary, trip purpose, duration and location were self-reported. Total trip duration was also derived as the difference between start and end time, while trip distance was obtained retrospectively feeding origin and destination coordinates to the Google Maps Application Programming Interfaces (API), which returned the fastest route per mode between origin and destination.

Three secondary exposure variables were developed to explore differences between groups of individuals. First, participants were categorized as using a 'main mode' of travel based on furthest daily distance (levels: walking, cycling, car, public transport). Further 
Table 2

Summary statistics of outcomes, exposures and other covariates.

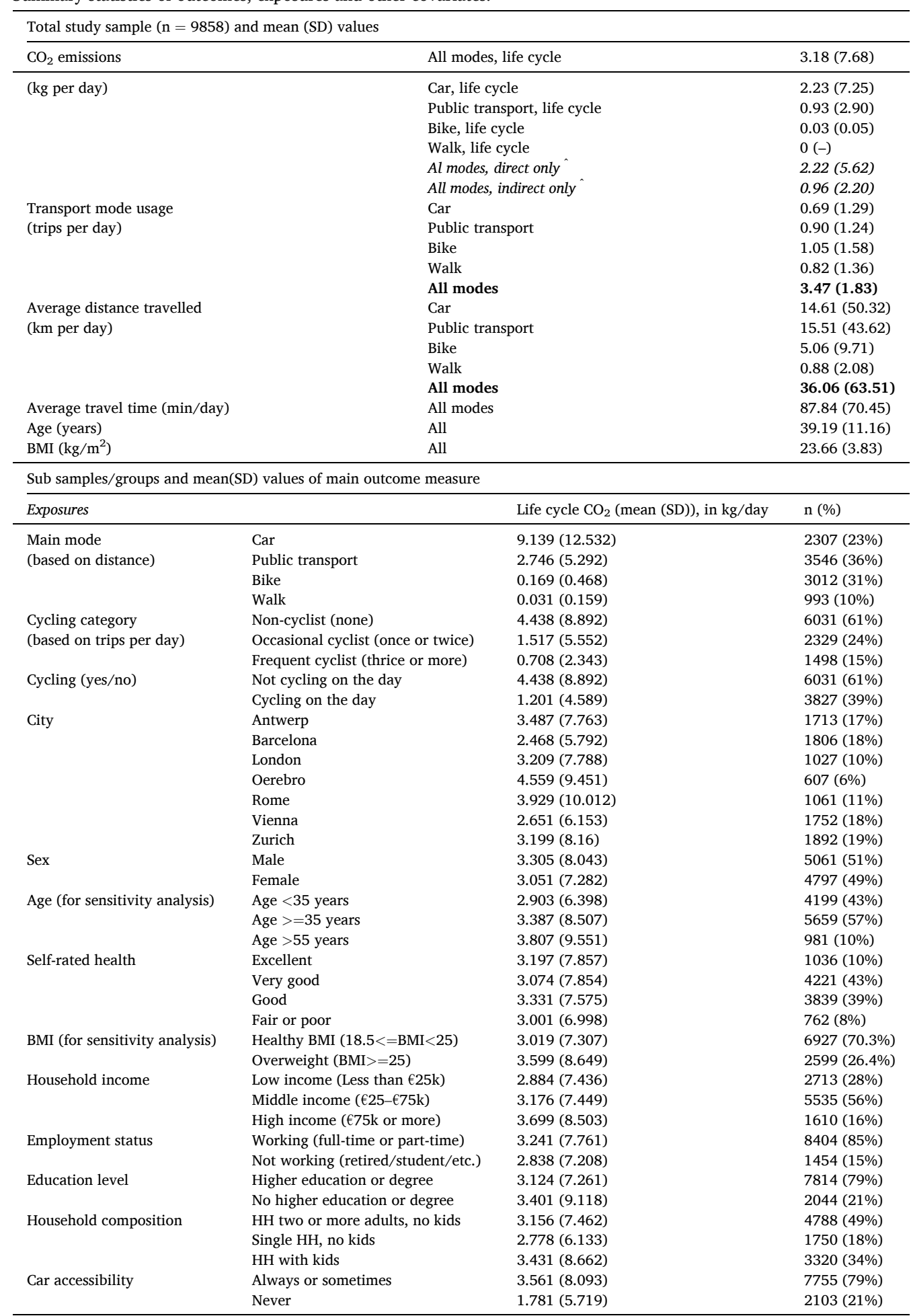

'Direct: tailpipe emissions. ' Indirect: well-to-tank (fuel/energy production) plus vehicle manufacture. BMI: body mass index. 
categorizations based on cycling frequency included a dichotomous variable of 'cycling' on the diary day (yes/no) as well as a trichotomous variable characterizing participants as 'frequent cyclist' (three or more times a day), 'occasional cyclist' (once or twice a day), or 'non-cyclist' (none). Table 2 shows sample sizes and mean (SD) values of the primary outcome variable for each group.

\subsection{Outcome variables: carbon dioxide emissions}

The primary outcome (or dependent variable) of interest was daily life cycle $\mathrm{CO}_{2}$ emissions (mass of carbon dioxide in gram or kilogram per day) attributable to passenger travel. Life cycle $\mathrm{CO}_{2}$ emissions categories considered were operational emissions, energy supply emissions and vehicle production emissions.

First, operational emissions were derived for each trip based on trip distance (computed from travel diary data), 'hot' carbon emissions factors, emissions from 'cold starts' (for cars only) and vehicle occupancy rates (passengers/vehicle) that varied by trip purpose. The method for cars and vans considered mean trip speeds (derived from the travel diaries), location-specific vehicle fleet compositions (taking into account the types of vehicle operating in the vehicle fleets during the study period) and the effect of 'real world driving' (adding 22\% to carbon emissions derived from 'real world' test data based on ICCT (2017)) to calculate the so called 'hot' emission of $\mathrm{CO}_{2}$ emitted per car-km. For motorcycle, bus and rail, operational emissions per vehicle-km were taken from BEIS (2019). The use of data from a UK study is a reasonable assumption as vehicle technology does not vary significantly across Europe, given the international nature of the vehicle market which is dominated by a relatively small number of manufacturers. An average urban bus in 2016 used about $34.2 \mathrm{~L}$ of diesel per $100 \mathrm{~km}$ and emitted about $1.24 \mathrm{kgCO} 2 /$ vehicle-km. The growing share of hybrid ICE (up to $20 \%$, depending on the city) and battery electric (only small at present) buses in the fleets is gradually improving these figures, which is taken into account in the study. Vehicle fuel type shares (gasoline, diesel, electric, other) and average occupancy rates for each city were based on international databases, including IIASA's Greenhouse gas Air pollution INteractions and Synergies (GAINS) and Eurostat's transport and energy data (Eurostat, 2016, 2020; IEA, 2015; IIASA, 2014). During the study period, buses were mainly powered by diesel powertrains; motorcycles were $100 \%$ gasoline; and urban rail was $100 \%$ electric. Public transport occupancy rates varied somewhat across cities. For instance for city buses, we assumed 28 passengers/vehicle in Barcelona, 21 in London, 17 in Rome, and 9 in Örebro (Adra et al., 2004; BEIS, 2019; EEA, 2016). Together with bus/rail split in trip rates obtained from EPOMM (2020), this translated into city-specific per passenger- $\mathrm{km}$ emission rates, as shown in Table 1.

For cars, 'cold start' excess emissions were added to 'hot' emissions based on the vehcile fleet composition, ambient temperatures (see Supplementary Table S13) and trip distances observed in each city: across the seven cities, cold start emissions averaged 126 (SD 42) $\mathrm{gCO}_{2}$ per car trip, with the trip share of a car operating with a 'cold' engine averaging 13 (SD 8) percent. Cold start emissions were higher-than-average in colder climates such as Orebro and Zurich, and lower in warmer ones such as Barcelona.

Second, carbon emissions from energy supply considered upstream emissions from the extraction, production, generation and distribution of energy supply, with values taken from international databases for fossil fuel emissions (2016; JEC, 2014; Odeh et al., 2013) and emissions from electricity generation and supply (Ecometrica, 2011). Third, vehicle life cycle emissions considered emissions from the manufacture of vehicles, with aggregate carbon values per vehicle type (cars, motorcycles, bikes and public transport vehicles) derived assuming typical lifetime mileages, mass body weights, material composition and material-specific emissions and energy use factors. The main functional relationships and data are provided in the Supplementary Information. The derived emissions rates are shown in Table 1 for each city, disaggregated by emissions category and transport mode.

Total daily emissions were calculated as the sum of emissions for each trip, mode and purpose (e.g. the sum of 4 trips on a given day $=$ trip 1: home to work by car, trip 2: work to shop by bike, trip 3: shop to work by bike; and trip 4: work to home by car). Secondary outcomes of interest were total life cycle $\mathrm{CO}_{2}$ emissions for four aggregated journey purposes: (1) work or education/school trips; (2) business trips; (3) social or recreational trips; and (4) shopping, personal business, escort or 'other' trips.

\subsection{Covariates}

A number of covariates (independent variables) were hypothesized to confound the association between carbon emissions and transport mode choice and use (e.g. Brand et al., 2013; Büchs and Schnepf, 2013; Goodman et al., 2019). Demographic and socioeconomic covariates considered in the analyses were age, sex, employment status, household income, educational level, and household composition (e.g. single occupancy, or having children or not). Vehicle ownership covariates considered were car accessibility, having a valid driving license, and bicycle accessibility. Health covariates considered were self-rated health status and Body Mass Index (BMI), which have been shown to influence motorized travel and transport $\mathrm{CO}_{2}$ emissions (Goodman et al., 2012). The perceived walking times to the nearest bus stop, tram stop or railway station were included as public transport accessibility measures. All of the covariates were self-reported. BMI was derived from self-reported weight and height as weight $(\mathrm{kg}) / \mathrm{height}(\mathrm{m})^{2}$ (Dons et al., 2018).

\subsection{Statistical analysis and modelling}

In a first step, bivariate analyses were performed to assess the association between transport-related $\mathrm{CO}_{2}$ emissions, the exposure variables, and the potential covariates. Only covariates with p-value $<0.1$ were included in further analysis. In a second step, differences in $\mathrm{CO}_{2}$ emissions between the different transport mode users were identified by using linear mixed-effects models (Baltagi, 2008) with city as a random effect (to take account of correlation among responses from the same city). The analysis used multiple data points for each individual, obtained on different weekdays. This justified using a multi-level modelling approach (Bryk and Raudenbush, 2002); we therefore included 'individual ID' and 'weekday' (level 1) as random effects, nested within city (level 2). 
Because $\mathrm{CO}_{2}$ emissions were heavily skewed towards the right (see also Fig. 1), we applied the transformation 'ln $([x /$ mean $(x)]+$ 0.01 )' (adding 0.01 to avoid turning zeros into missing values) in the comparative analysis. This improved our regression diagnostics, with residuals closer to a normal distribution and their variance less heteroscedastic. Note a log transformation changes the focus from absolute to relative or percentage change; therefore, any regression coefficient $\beta$ is a mean difference of the log outcome comparing adjacent units of a predictor. This is practically useless, so we exponentiate the parameter $\mathrm{e}^{\beta}$ and interpret this value as a geometric mean difference (Vittinghoff et al., 2012).

Three regression models were fitted. First, 'model $0^{\prime}$ fitted an unadjusted (exposure only) fixed effects model; second, 'model 1 ' fitted a hierarchical (two levels) mixed effects model (Bryk and Raudenbush, 2002) partially adjusted by socio-demographic covariates of sex, age, education level, employment status, household income, and household composition; and third, model 2 fitted a hierarchical (two levels) mixed effects model fully adjusted by all covariates from model 1 and additionally other covariates of interest (those found to be statistically significant in previous literature described earlier): holding a valid driving license, access to a car or van, bicycle ownership, self-rated health, BMI, walking-time accessibility to the nearest bus stop, and walking-time accessibility to the nearest train station. Age was included as a continuous variable as a proxy for time. As described earlier, city, participant and weekday were included as random effects in the mixed effects models (models 1 and 2). The same set of models were fitted for each of the four journey purposes. Equation (1) provides the general formula for the fully-adjusted model of the main exposure variable (daily transport mode usage), log-transformed $\mathrm{CO}_{2}$ emissions as the dependent variable, and a set of covariates with fixed effects $\left(\beta_{i}\right)$ and random effects $\left(\rho_{j}\right)$. For model definitions of the three secondary exposures, replace 'transport mode usage' with categorical variables 'main mode of travel', 'cycling frequency', and 'cyclist/non-cyclist'.

$$
\begin{aligned}
\mathrm{CO}^{*}= & \beta_{1} \times f_{\text {cycle }}+\beta_{2} \times f_{\text {car }}+\beta_{3} \times f_{P T}+\beta_{4} \times f_{\text {walk }}+\beta_{5} \times \text { sex }+\beta_{6} \times \text { age }+\beta_{7} \times \text { educ }+\beta_{8} \times \text { employ }+\beta_{9} \times \text { HHinc }+\beta_{10} \\
& \times \text { HHcomp }+\beta_{11} \times \text { license }+\beta_{12} \times \text { caraccess }+\beta_{13} \times \text { bikeaccess }+\beta_{14} \times \text { health }+\beta_{15} \times \text { BMI }+\beta_{16} \times \text { PTbus }+\beta_{17} \times \text { PTrail }+\rho_{1} \\
& \times \text { weekday }+\rho_{2} \times \text { participant }+\rho_{3} \times \text { city }+\epsilon
\end{aligned}
$$

where

Dependent variable: $\mathrm{CO}^{*}=\ln \left(\left[\mathrm{CO}_{2} /\right.\right.$ mean $\left.\left.\left(\mathrm{CO}_{2}\right)\right]+0.01\right)$;

Exposure variables: $f_{\text {mode. } x}=$ trips per day by mode $\mathrm{x}$;

Covariates: sex, age, educ (highest level of education), employ (employment status), HHinc (household income), HHcomp (household composition), licence (driving licence), caraccess (car access), bikeaccess (bike access), health (self-rated health status), BMI (body mass index), PTbus (walking time to nearest bus stop), PTrail (walking time to nearest train station), weekday, participant, city;

$\beta_{I}=$ vector of fixed effects; $\rho_{j}=$ vector of random effects. $\epsilon=$ vector of random errors.

Potential interaction by sex, employment status, income, car access, BMI and city were investigated with Type II Wald chisquare tests in the fully-adjusted models. We observed significant interactions for some transport modes (e.g. use of all modes and car access; public transport use and gender; car use and income); therefore, all models' sensitivity to different levels of the above factors were tested. We also tested the models' sensitivity to a number of other factors: age (' $<35$ years'), working status ('working'), car access ('not having access to a car'), body weight ('being overweight'), household income ('high income') and city (Table 2). Participants

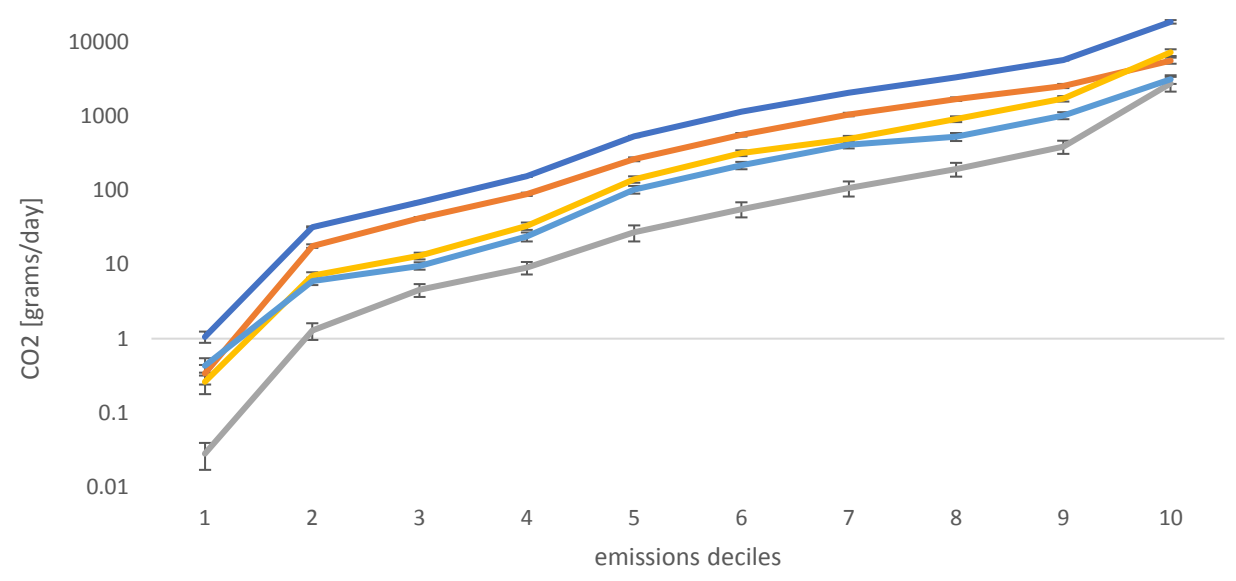

-all purposes $\longrightarrow$ work or education $\longrightarrow$ business $\longrightarrow$ social or recreational $\longrightarrow$ shoping, PB, escort or other

Fig. 1. Distributions of mean life cycle $\mathrm{CO}_{2}$ emissions by travel emissions decile, subdivided by journey type (log-normal plot, error bars are 95\% CIs). 
were also ranked according to their $\mathrm{CO}_{2}$ emissions (all travel and by trip purpose) then split into ten emissions deciles. Chi-square tests were performed on selected covariates to profile the 'bottom' and 'top' deciles. Possible mediation of the effect of transport mode use on $\mathrm{CO}_{2}$ emissions was assessed for three potential mediators: total daily distance travelled, BMI and self-rated health (VanderWeele, 2016; Wanner et al., 2012). Only observations without missing data were included. R statistical software v3.6.1 was used for all analyses.

\section{Results}

\subsection{Sample description and summary statistics}

The final sample included 3836 participants who had completed 9858 one-day travel diaries reporting 34,203 trips (Table 2). The sample was well balanced between male and female, and between the seven cities. Participants were highly educated with $79 \%$ of the participants having at least a secondary or higher education degree. Aged between 16 and 91, the majority of participants were employed full-time (66\%), with $72 \%$ on middle to high household incomes (i.e. $>€ 25 \mathrm{k}$ ) and $34 \%$ reported to have children living at home. The share of participants without access to a car was $21 \%$. While cycling and public transport were the most frequent transport modes among our participants, people travelled furthest by public transport and car. Transport mode usage was similar between sexes, with a slightly higher prevalence of male cyclists and drivers vs. female walkers and public transport users. Participants reported an average of 3.47 (SD 1.83) trips per day ranging from 3.10 (SD 1.63) trips per day in Rome to 3.75 (SD 2.0) trips per day in Antwerp (Table 2). The observed cycling trip share for our sample was between $17 \%$ in Barcelona and $54 \%$ in Antwerp (Supplementary Table S1), i.e. somewhat higher than cycling shares reported for the cities (EPOMM, 2020) and a direct result of purposively oversampling cyclists. Reported trip durations and distances varied between subjects and cities, with respondents travelling on average 36.1 (SD 63.5) km a day and for 87.8 (SD 70.4) min a day. Average trip lengths across the cities were 1.1 (SD 1.6) km for walking, 5.0 (SD 5.3) km for cycling, 20.5 (SD 45.9) km for driving and 16.7 (SD 33.6) km for public transport. These are comparable to travel statistics for European cities (JRC, 2013). Further results for each city are given in Supplementary Table S3.

\subsection{Levels and sources of life cycle $\mathrm{CO}_{2}$ emissions}

Life cycle $\mathrm{CO}_{2}$ emissions from all travel activity were 3.18 (SD 7.68) kilograms of $\mathrm{CO}_{2}\left(\mathrm{kgCO}_{2}\right)$ per person per day, with the majority from car travel at 2.23 (SD 7.25) $\mathrm{kgCO}_{2}$ /day - i.e. $70 \%$ of the daily total (see Table 2). In contrast, life cycle emissions from cycling

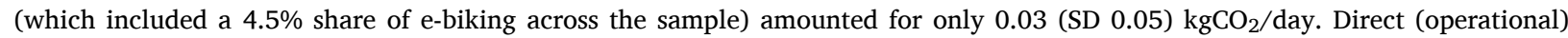
emissions from all travel activity made up the majority (70\%) of total life cycle emissions. While travel to work or place of education produced the largest share of $\mathrm{CO}_{2}$ emissions (37\%), there were also considerable contributions from social and recreational trips (34\%), business trips (11\%) and travel for shopping or personal business (17\%). Fig. 1 shows a highly unequal distribution of emissions. It also shows that the top decile of emitters were responsible for $59 \%$ (all purposes), $47 \%$ (work or education), $78 \%$ (business), $67 \%$ (social or recreational) and 58\% (shopping, personal business, escort or other) of the respective life cycle $\mathrm{CO}_{2}$ emissions. Those in the top decile were more likely to be male, have higher household incomes, holding a driving license and always have access to a car, be in full-time employment, have higher BMI, have poor bus or train accessibility and live in Orebro, Antwerp or Rome. In contrast, those in the bottom decile of emitters were more likely to be female, economically inactive or a student, living in a household without kids, be on lower household incomes, not to hold a driving license, without access to a car, own a bike, have lower BMI, live nearer to train stations, and live in Barcelona or London. To explain this it is worth highlighting that while Antwerp and Orebro had significantly ${ }^{2}$ higher cycling trip shares amongst the case study cities, they also had higher car shares (together with Rome) and low walking shares (also together with Rome). On the contrary, Barcelona and London had lower car trip shares (like Vienna and Zurich) and higher walking shares (Supplementary Table S3).

In our sample, respondents in Orebro and Rome produced significantly higher-than-average $\mathrm{CO}_{2}$ emissions $(\mathrm{mean} 4.56 \mathrm{kgCO} 2 / \mathrm{day}$ and $3.93 \mathrm{kgCO}_{2}$ /day, respectively) due to the higher car mode shares, while those in Barcelona and Vienna produced lower emissions (mean $2.47 \mathrm{kgCO}_{2}$ /day and $2.65 \mathrm{kgCO}_{2} /$ day, respectively) due to higher share of walking (Barcelona) and a combination of lower car and higher public transport shares (Vienna) (Table 2 and Supplementary Table S3). Those in Antwerp had the highest active travel share, but also higher (than sample average) car and lower public transport shares, resulting in higher than average $\mathrm{CO}_{2}$ emissions overall (mean $3.49 \mathrm{kgCO}_{2}$ /day). These figures are generally in line with regional per capita $\mathrm{CO}_{2}$ emissions estimates. Differences between cities can partially be explained by differences in sample demographics, socio-economics and observed mode shares (Supplementary Table S1 and Table S3).

\subsection{Transport mode usage}

We found statistically significant associations between life cycle $\mathrm{CO}_{2}$ emissions and transport mode usage across all modes of travel (Table 3a): those who cycled or walked more had lower daily mobility-related $\mathrm{CO}_{2}$ emissions, while those who drove more or used public transport more had higher daily total $\mathrm{CO}_{2}$ emissions. In the fully-adjusted model (model 2), log-transformed life cycle carbon

${ }^{2}$ Comparing deciles with chi-square tests of independence. 
Table 3

Results from the linear fixed-effects and mixed-effects models for the four exposures $(n=9858)$. Full models are presented in the Supplementary Information.

\begin{tabular}{|c|c|c|c|c|c|c|}
\hline & \multicolumn{2}{|c|}{ Model 0: unadjusted (fixed effects) } & \multicolumn{2}{|c|}{ Model 1: partly adjusted (mixed effects) ${ }^{\dagger}$} & \multicolumn{2}{|c|}{ Model 2: fully adjusted (mixed effects) ${ }^{\#}$} \\
\hline & Coefficient $(95 \%$ CI) & p-value & Coefficient $(95 \% \mathrm{CI})$ & p-value & Coefficient $(95 \% \mathrm{CI})$ & p-value \\
\hline \multicolumn{7}{|c|}{ (a) Association between log-transformed life cycle $\mathrm{CO}_{2}$ emissions and transport mode usage (trips/day) (full model in Table S4) } \\
\hline Bike & $-0.154(-0.172$ to -0.137$)$ & $<0.0001$ & $-0.16(-0.179$ to -0.142$)$ & $<0.0001$ & $-0.151(-0.17$ to -0.132$)$ & $<0.0001$ \\
\hline Car & $0.997(0.976-1.017)$ & $<0.0001$ & $0.974(0.953-0.996)$ & $<0.0001$ & $0.962(0.94-0.983)$ & $<0.0001$ \\
\hline Public transport & 0.741 ( 0.719 to 0.763$)$ & $<0.0001$ & $0.737(0.714-0.76)$ & $<0.0001$ & $0.748(0.724-0.771)$ & $<0.0001$ \\
\hline Walk & $-0.287(-0.305$ to -0.269$)$ & $<0.0001$ & $-0.278(-0.297$ to -0.259$)$ & $<0.0001$ & $-0.273(-0.292$ to -0.254$)$ & $<0.0001$ \\
\hline \multicolumn{7}{|c|}{ (b) Association between log-transformed life cycle $\mathrm{CO}_{2}$ emissions and main transport mode categories (full model in Table S6) } \\
\hline Bike & 0 & - & 0 & - & 0 & - \\
\hline Car & 3.89 (3.84-3.939) & $<0.0001$ & $3.881(3.829-3.932)$ & $<0.0001$ & $3.866(3.813-3.919)$ & $<0.0001$ \\
\hline Public transport & $2.599(2.554-2.643)$ & $<0.0001$ & $2.624(2.575-2.673)$ & $<0.0001$ & $2.635(2.586-2.684)$ & $<0.0001$ \\
\hline Walk & $-1.071(-1.137$ to -1.005$)$ & $<0.0001$ & $-0.956(-1.023$ to -0.888$)$ & $<0.0001$ & $-0.931(-0.999$ to -0.862$)$ & $<0.0001$ \\
\hline \multicolumn{7}{|c|}{ (c) Association between log-transformed life cycle $\mathrm{CO}_{2}$ emissions and cycling frequency categories (full model in Table S7) } \\
\hline None & 0 & - & 0 & - & 0 & - \\
\hline Once or twice a day & $-1.697(-1.781$ to -1.612$)$ & $<0.0001$ & $-1.768(-1.855$ to -1.681$)$ & $<0.0001$ & $-1.747(-1.835$ to -1.659$)$ & $<0.0001$ \\
\hline Three + times a day & $-2.016(-2.116$ to -1.916$)$ & $<0.0001$ & $-2.071(-2.177$ to -1.966$)$ & $<0.0001$ & $-2.038(-2.145$ to -1.932$)$ & $<0.0001$ \\
\hline \multicolumn{7}{|c|}{ (d) Association between log-transformed life cycle $\mathrm{CO}_{2}$ emissions and cycling (yes/no) (full model in Table S8) } \\
\hline Not cycling & 0 & - & 0 & - & 0 & - \\
\hline Cycling & $-1.822(-1.893$ to -1.75$)$ & $<0.0001$ & $-1.875(-1.952$ to -1.797$)$ & $<0.0001$ & $-1.848(-1.927$ to -1.769$)$ & $<0.0001$ \\
\hline
\end{tabular}

${ }^{\dagger}$ Model 1 adjusted for sex, age, education level, employment status, household income, household composition; city and person as random effects.

\# Model 2 adjusted for sex, age, education level, employment status, household income, household composition, driver license, car access, bike access, self-rated health, BMI, bus accessibility, rail accessibility; city, person and day of the week as random effects.

emissions decreased by a factor of 0.15 (95\%CI 0.13-0.17) for each additional cycling trip. They also decreased by a factor of 0.96 (95\%CI 0.94-0.98) for one less car trip. When converting the log-transformed results into physical units, we find that for each avoided car trip daily life cycle $\mathrm{CO}_{2}$ emissions from transport decreased by $62 \%$ (95\%CI 61-63\%) while for each additional bike trip life cycle $\mathrm{CO}_{2}$ emission decreased by $14 \%$ (95\%CI $12-16 \%$ ). While this may be confusing at first, it is the result of converting log-transformed outcomes to physical units, as is common practice in such regression models (Vittinghoff et al., 2012). To derive percentage changes of the untransformed outcome, we exponentiated the regression coefficient, subtracted 1 and multiplied by 100 . For example, the coefficient of -0.962 for one less car trip (see also Table 3 ), we first exponentiate $(=0.382)$, then subtract 1 (=-0.618) and multiply by $100(=61.8)$ to obtain a $62 \%$ decrease. Those who made one less car trip and one more bike trip a day (a proxy for mode shift from car to bike) decreased life cycle $\mathrm{CO}_{2}$ emissions from transport by $67 \%$ (95\%CI 66-68\%).

Adjusting for demographic, socio-economic, other individual variables as well as including random effects parameters (city, individual, weekday) only slightly changed the estimates in the partly and the fully adjusted models (model 1 and model 2) compared to the unadjusted model (model 0). The addition of car availability and bus station accessibility in the fully adjusted model (model 2) slightly lowered the estimate for car but increased the estimate for public transport use compared to the unadjusted (0) and partly adjusted models (1).

The effects of transport mode use on transformed carbon emissions was partially mediated via total distance travelled (see Fig. 2): the indirect effects of total distance travelled were +0.13 for car use ( $13 \%$ mediated), -0.02 for cycling ( $14 \%$ mediated), +0.10 for public transport use (13\% mediated), and -0.05 for walking ( $18 \%$ mediated). Neither BMI nor health status mediated this association.

A series of sensitivity analyses largely confirmed our results (Fig. 3a): excluding participants older than 35 or on lower incomes did not change our conclusions; and differences between those 'working' and 'not working' and those being 'overweight' (above $25 \mathrm{~kg} / \mathrm{m}^{2}$ ) and 'healthy weight' were small. For people who did not have access to a car the effects were larger for motorized travel and smaller for active travel, suggesting that active travel for non-car owning households may substitute for public transport and other active travel.

The associations between log-transformed life cycle $\mathrm{CO}_{2}$ emissions for the four trip purposes (secondary outcomes) and transport mode usage were also largely significant (Table 4a and Supplementary Fig. S3a). Cycling frequency had larger effects on emissions from commuting to work or place of education than on emissions from all purposes (primary outcome models). Motorized transport mode use showed larger effects on life cycle $\mathrm{CO}_{2}$ emissions from social, shopping and recreational travel than for work/business travel. The 'economically inactive' (home duties, retired, unemployed, etc.) showed significantly higher emissions for social, recreational, shopping and personal business purposes, with lower emissions from work or educational trips, as expected. Those with children living at home had significantly lower business, social and recreational emissions, while emissions from shopping, personal business and escort trips were higher. Poor bus accessibility and better car access meant higher emissions from work or educational trips.

\subsection{Main mode of travel (by daily distance travelled)}

We also found statistically significant associations between life cycle $\mathrm{CO}_{2}$ emissions and the main modes of travel according to daily distance travelled (Table $3 \mathrm{~b}$ ): when compared to using a bike as the main mode, using the car or public transport increased $\mathrm{CO}_{2}$ while walking decreased $\mathrm{CO}_{2}$. In the fully adjusted model (model 2) $\mathrm{CO}_{2}$ emissions were 98 (95\% CI 98-98) percent higher for using a car or

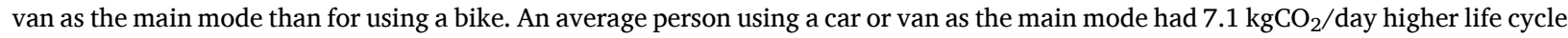




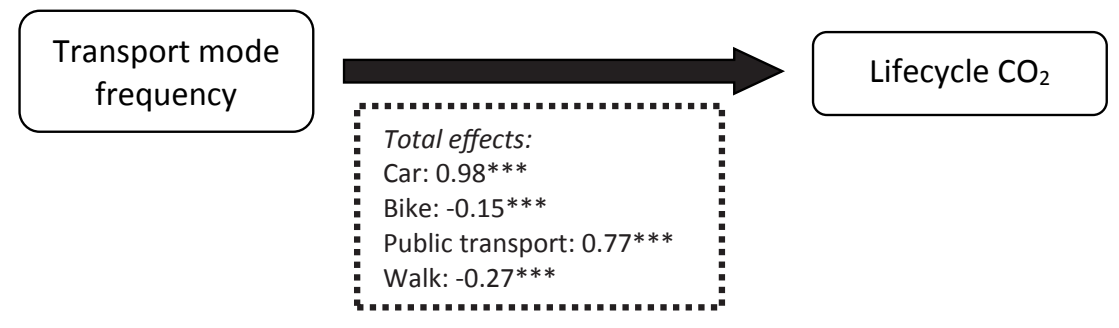

A
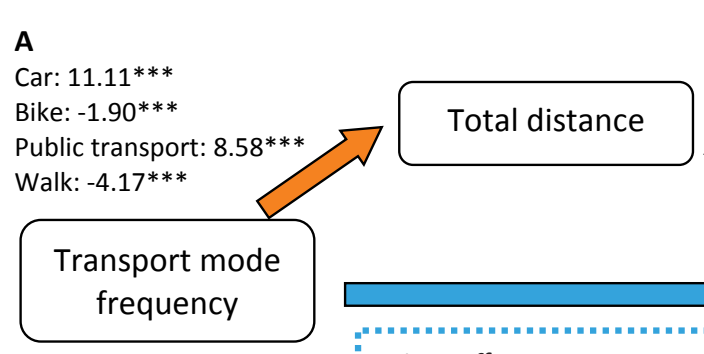

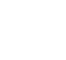


Table 4

Results from the fully-adjusted mixed-effects models for the four exposures, by trip purpose.

\begin{tabular}{|c|c|c|c|c|c|c|c|c|}
\hline \multirow[t]{2}{*}{$\mathrm{n}=9858$} & \multicolumn{2}{|l|}{ Work or education ${ }^{\#}$} & \multicolumn{2}{|l|}{ Business $\#$} & \multicolumn{2}{|l|}{ Social or recreational ${ }^{\#}$} & \multicolumn{2}{|c|}{ Shopping, personal business, escort, or 'other' * } \\
\hline & Coefficient (95\% CI) & $\mathrm{p}$-value & Coefficient (95\% CI) & $\mathrm{p}$-value & Coefficient (95\% CI) & $\mathrm{p}$-value & Coefficient (95\% CI) & $\mathrm{p}$-value \\
\hline \multicolumn{9}{|c|}{ (a) Association between log-transformed life cycle $\mathrm{CO}_{2}$ emissions and transport mode usage (trips/day) (full model in Table S9) } \\
\hline Bike & -0.24 ( -0.27 to -0.209$)$ & $<0.001$ & $0.019(-0.008$ to 0.046$)$ & 0.174 & $0.062(0.031-0.094)$ & $<0.001$ & $0.158(0.126-0.189)$ & $<0.001$ \\
\hline Car & $0.191(0.157-0.226)$ & $<0.001$ & $0.172(0.141-0.203)$ & $<0.001$ & $0.725(0.689-0.761)$ & $<0.001$ & $0.826(0.79-0.861)$ & $<0.001$ \\
\hline PT & $0.412(0.375-0.449)$ & $<0.001$ & $0.168(0.134-0.201)$ & $<0.001$ & $0.475(0.436-0.514)$ & $<0.001$ & $0.393(0.354-0.431)$ & $<0.001$ \\
\hline Walk & $-0.272(-0.302$ to -0.242$)$ & $<0.001$ & $-0.064(-0.091$ to -0.037$)$ & $<0.001$ & $-0.092(-0.123$ to -0.061$)$ & $<0.001$ & $-0.025(-0.056$ to 0.006$)$ & 0.112 \\
\hline \multicolumn{9}{|c|}{ (b) Association between log-transformed life cycle $\mathrm{CO}_{2}$ emissions and main transport mode categories (full model in Table S10) } \\
\hline Bike & 0 & - & 0 & - & 0 & - & & - \\
\hline Car & $1.532(1.424-1.641)$ & $<0.001$ & $0.762(0.662-0.863)$ & $<0.001$ & $2.281(2.164-2.397)$ & $<0.001$ & $1.987(1.867-2.108)$ & $<0.001$ \\
\hline PT & $1.873(1.774-1.973)$ & $<0.001$ & $0.469(0.378-0.561)$ & $<0.001$ & $1.002(0.895-1.108)$ & $<0.001$ & $0.677(0.566-0.787)$ & $<0.001$ \\
\hline Walk & $-0.648(-0.787$ to -0.509$)$ & $<0.001$ & $-0.141(-0.27$ to -0.011$)$ & 0.033 & $-0.784(-0.934$ to -0.634$)$ & $<0.001$ & $-0.462(-0.617$ to -0.306$)$ & $<0.001$ \\
\hline \multicolumn{9}{|c|}{ (c) Association between log-transformed life cycle $\mathrm{CO}_{2}$ emissions and cycling frequency categories (full model in Table S11) } \\
\hline None & 0 & - & 0 & - & 0 & - & & - \\
\hline 1-2 times & $-1.086(-1.188$ to -0.983$)$ & $<0.001$ & $-0.433(-0.522$ to -0.344$)$ & $<0.001$ & $-0.865(-0.977$ to -0.754$)$ & $<0.001$ & $-0.77(-0.882$ to -0.658$)$ & $<0.001$ \\
\hline $3+$ times & $-1.498(-1.622$ to -1.374$)$ & $<0.001$ & $-0.218(-0.324$ to -0.111$)$ & $<0.001$ & $-0.756(-0.89$ to -0.622$)$ & $<0.001$ & $-0.344(-0.479$ to -0.21$)$ & $<0.001$ \\
\hline \multicolumn{9}{|c|}{ (d) Association between log-transformed life cycle $\mathrm{CO}_{2}$ emissions and cycling (yes/no) (full model in Table S12) } \\
\hline Not cycling & 0 & - & 0 & - & 0 & - & & - \\
\hline Cycling & $-1.229(-1.321$ to -1.136$)$ & $<0.001$ & $-0.356(-0.435$ to -0.277$)$ & $<0.001$ & $-0.826(-0.925$ to -0.727$)$ & $<0.001$ & $-0.617(-0.717$ to -0.517$)$ & $<0.001$ \\
\hline
\end{tabular}

\section{$\mathrm{PT}=$ public transport.}

\# Models are mixed effects models fully adjusted for sex, age, education level, employment status, household income, household composition, driver license, car access, bike access, self-rated health, BMI, bus accessibility, rail accessibility; city, person and day of the week as random effects. 
$\mathrm{CO}_{2}$ emissions than someone using a bike as their main mode of transport. A comparison with the results of the non-transformed model suggested that using a car or van increased emissions by $8.9 \mathrm{kgCO}_{2} /$ day when compared to cycling as the main mode (Supplementary Table S5 and Fig. S2) - suggesting the linear model slightly overestimated differences in emissions by main mode when compared to the (statistically superior) log-linear model. Those using public transport as the main mode had 71 (95\%CI 71-71) percent lower emissions than those mainly using a car, van or motorcycle; for an average person this difference equated to $5.1 \mathrm{kgCO} / \mathrm{day}$.

Again, the sensitivity analysis (Fig. 3b) largely confirmed our results. Total distance travelled partially (12\%) mediated the effects of main mode (by daily distance) on transformed life cycle $\mathrm{CO}_{2}$ emissions. The associations for log-transformed $\mathrm{CO}_{2}$ emissions by journey purpose were also all significant (Supplementary Table S10 and Fig. S3), with the strongest effects for mainly using public transport for work or education and car for social and shopping trips. Women, those with a degree or no access to a car had significantly lower work or education emissions. As expected, the economically inactive had significantly higher social, recreational and shopping/ personal business emissions, yet lower work/education emissions.

\subsection{Cycling frequency and cycling vs not cycling}

Associations between life cycle $\mathrm{CO}_{2}$ emissions and cycling frequency were all highly significant. Table $3 \mathrm{c}$ shows that in the fully adjusted model (model 2) life cycle $\mathrm{CO}_{2}$ emissions were 83 (95\%CI 81-84) percent lower for 'occasional cyclists' (i.e. those cycling 'once or twice a day') than for those who did not cycle; and they were even lower for 'frequent cyclists' (those cycling 'three or more times a day') with 87 (95\%CI 86-88) percent lower daily life cycle $\mathrm{CO}_{2}$. The sensitivity analysis (Fig. 3c) generally confirmed our results, with slightly higher effects for high earners and lower effects if you were younger or without access to a car. Regular cycling was also associated with reduced life cycle $\mathrm{CO}_{2}$ emissions for all the four trip purposes, with the strongest effect observed for commuting and social trips (Supplementary Table S11): cycling three or more times a day decreased life cycle $\mathrm{CO}_{2}$ emissions for work or education by 78 (95\%CI 75-80) percent, for social or recreational trips by 53 (95\%CI 46-59) percent, for shopping and personal business by 29 (95\%CI 19-38) percent, and for business travel by 20 (95\%CI 10-28) percent.

As expected, the binary cyclist/non-cyclist analysis showed similar effect sizes and correlations to the analysis of cycling frequency for both primary and secondary outcome measures. 'Cyclists' had 84 (95\%CI 83-85) percent lower life cycle $\mathrm{CO}_{2}$ emissions than 'noncyclists' (Table $2 \mathrm{~d}$ and Supplementary Table S12); this translated into 0.97 (95\%CI $0.54-1.74$ ) $\mathrm{kgCO}_{2} / \mathrm{day}^{\mathrm{lower}}$ life $\mathrm{cycle}^{\mathrm{CO}} \mathrm{CO}_{2}$ emissions for an average person who cycled. The sensitivity analysis showed that the effects were lower for the younger respondents and those without access to a car, and higher for those on higher incomes (Fig. 3d).
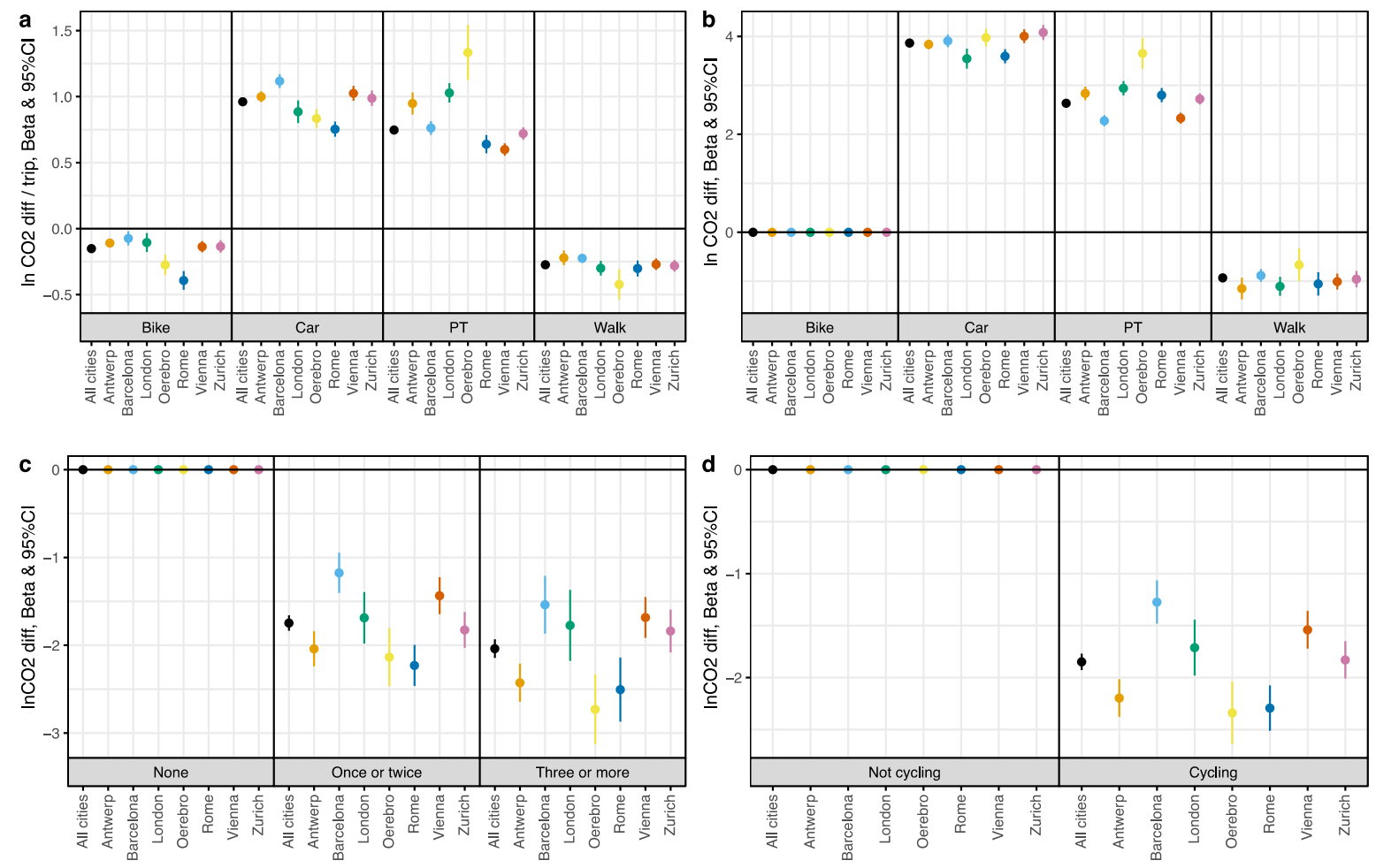

Fig. 4. Effect sizes from the fully adjusted model and sensitivity analyses (city stratification). Exposure variables: transport mode usage in panel a; main mode of transport (by distance) in panel b; cycling frequency in panel c; and cycling/not cycling in panel d. The dots indicate differences in $\mathrm{CO}_{2}$ emissions and the error bars indicate $95 \%$ CIs. 


\subsection{Sensitivity: city effects}

The random intercepts of city explained 2.2\% (a: transport mode usage), 5.4\% (b: main mode of transport), $2.6 \%$ (c: cycling frequency) and $2.5 \%$ (d: cycling yes/no) of the residual variance in the fully adjusted models. $\mathrm{Mean}^{\mathrm{CO}_{2}}$ emissions were significantly lower in Barcelona and Vienna and higher in Orebro and Rome (Table 2). Further sensitivity analyses of the fully adjusted models stratified by city showed that the effect estimates for cycling were generally the lowest in Barcelona and highest in Orebro and Rome (see Fig. 4). By comparison, $\mathrm{CO}_{2}$ effects for car travel were highest in Barcelona (and Vienna to some extent) and lowest in London and Rome.

\section{Discussion}

\subsection{Summary of results}

This paper started on the premise that we still do not know very much about how much carbon from passenger transport is saved overall - by active travel. In this multi-city study with thousands of participants providing nearly 10,000 valid person-days of travel activity, we found highly significant associations between transport mode choice and total life cycle $\mathrm{CO}_{2}$ emissions. We showed that cyclists had significantly lower total $\mathrm{CO}_{2}$ emissions than non-cyclists. More cycling or walking decreased mobility-related life cycle $\mathrm{CO}_{2}$ emissions - suggesting that active travel indeed substitutes for motorized travel (i.e. this was not just additional travel over and above motorized travel). This means that even if not all car trips could be substituted by bicycle trips the potential for decreasing emissions is very high. A number of sensitivity analyses that tested for potential interactions and biases in the study sample confirmed our main results and provided new insights into differences of emission levels and exposures by city, journey purpose and key covariates. The differences in mean emissions and effect sizes in the seven cities may be explained by contextual factors such as differences in modal shares, mode trip lengths, and the provision (or not) of good public transport services and active travel infrastructure - it may also be due to differences in sampling (Raser et al., 2018). The analysis of emissions for each trip purpose highlighted the relative importance of emissions from non-work/business trips, particularly trips for social and shopping purposes.

\subsection{Comparison with previous studies}

Mean total $\mathrm{CO}_{2}$ emissions of $3.18 \mathrm{kgCO}_{2} /$ day were much higher than the median $\left(0.81 \mathrm{kgCO}_{2} /\right.$ day $)$ and near the upper end of the derived interquartile range (0.07-3.27 $\mathrm{kgCO}_{2}$ per day), confirming a positively skewed distribution of emissions. In other words, a relatively small share of individuals was responsible for the vast majority of carbon emissions, a finding that is very much in line with the evidence on unequal carbon emissions distributions (Brand and Boardman, 2008; Büchs and Schnepf, 2013; Ko et al., 2011; Preston et al., 2013; Susilo and Stead, 2009). Our findings that the likelihood of being in top or bottom emissions decile depended on demographic, socio-economic, car availability, health, public transport accessibility and contextual factors further support the growing evidence on travel emissions inequalities (Banister, 2018; Bel and Rosell, 2017; Brand, 2008; Ko et al., 2011).

The analysis of transport mode use as the main exposure showed that each additional cycling trip reduced life $\mathrm{cycle}^{\mathrm{CO}} \mathrm{C}_{2}$ emissions from all travel activity by about $14 \%$ when compared to baseline emissions. On average, those who did one less trip by car and one more by bike or public transport decreased emissions by $67 \%$ and $19 \%$ respectively. To further aid interpretation of the factorial results we need to apply the percentage changes to baseline (or mean) levels of our measured outcomes. For example, an average person

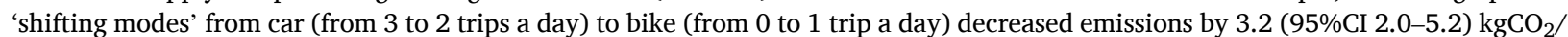
day. Similarly, a person 'shifting modes' from car (from 3 to 2 trips a day) to public transport (from 0 to 1 trip a day) decreased emissions by 0.9 (95\% $0.6-1.5) \mathrm{kgCO}_{2}$ /day. If $10 \%$ of the population were changing travel behavior this way, emissions would be expected to decrease by about $10 \%$ (car $\rightarrow$ bike) and $3 \%$ (car $\rightarrow$ public transport). The size and direction of emissions changes are in line with some of the few empirical (Brand et al., 2013; Goodman et al., 2012) and scenario/modelling (Goodman et al., 2019; Rabl and de Nazelle, 2012; Tainio et al., 2017; Woodcock et al., 2018) studies in this area.

The differences in emissions between people using different modes for the majority (defined by max. distance travelled) of their daily travel were also highly significant, although the effects were partially (12\%) mediated by total daily distance travelled. Our

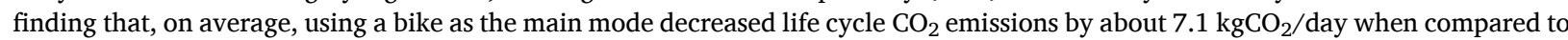
using a car or van suggests that making more sustainable choices on to how we get from A to B has significant carbon benefits. Similarly, our finding that doing at least one trip a day by bike significantly decreased mobility-related life cycle $\mathrm{CO}_{2}$ emissions provides further evidence of mode substitution away from motorized travel.

Much of the research in this area has focused on travel activity and associated carbon emissions from work and business travel (Bearman and Singleton, 2014; Clark et al., 2016). In our study, commuting, education and business travel emissions represented 'only' about half (49\%) of total emissions, ranging from 39\% in Antwerp to $59 \%$ in London and Rome. The findings that life cycle $\mathrm{CO}_{2}$ emissions from social, shopping, personal business and recreational journeys were more strongly associated to car and, to some extent, public transport use suggest for research and policy to go beyond commuting and business travel and consider the whole range of journey purposes when investigating mode shift away from motorized to active travel (Brand et al., 2013). This seems to be particularly important with the growing shares of the elderly in the population. Shopping and personal business trips were found to be significantly shorter, therefore increasing the potential for mode shift to active travel.

The mediation analysis by distance travelled indicated that lower carbon emissions for cyclists was unlikely to be entirely caused by increased bike usage. The remaining emissions difference might be explained by distance-related factors that influence mode choice 
such as urban form and location of housing, services and jobs (Banister et al., 1997; Beenackers et al., 2012; Curtis, 1996; Welch, 2013).

While focusing on cycling above we also found that using public transport was more beneficial than private motorized transport across all exposure measures, thus confirming findings from the large body of literature that already exists in this area (see e.g. Banister, 2008; Graham-Rowe et al., 2011; Nieuwenhuijsen, 2020; Woodcock et al., 2009).

Last but not least, it is important to highlight that increased active and reduced motorized travel have significant benefits beyond climate change mitigation, particularly with regards to improving population health through increased physical activity and reduced local air pollution (Nieuwenhuijsen, 2020; Shaw et al., 2014). The relative importance of these impacts depends on the context, but the evidence is convincing (Gössling et al., 2019; Götschi et al., 2020; Rodrigues et al., 2020).

\subsection{Potential limitations of the study, and how we addressed them}

In interpreting these findings we need to bear in mind the study's limitations. First, the recruitment and sampling strategy means that our study sample of adults living in urban areas cannot be assumed to be representative of the general population. Orebro was the lone city that made a concerted effort for random sampling, whereas in other cities an opportunistic recruitment strategy was followed (Dons et al., 2015). However, by oversampling some of the less frequent transport modes, we had a sufficiently large sample of cyclists in all cities to find statistically significant associations. Furthermore, we have made a concerted attempt to account for any potential bias in the study sample through application of multi-level modelling, adjusting for the key socio-demographic predictors/control variables, and conducting extensive sensitivity analyses of potential biases and interactions. We have confidence, therefore, that the findings are generalisable in the context of the adult population in European cities.

Second, recall bias and participant burden of a substantive survey instrument may have impacted the travel diary reporting, which may have reduced the number of reported trips. However, the observed trip frequencies (e.g. 3.47 trips per person per day on average) and mode shares (e.g. significantly higher cycling shares in Antwerp, lower cycling shares in Barcelona, higher public transport shares in London, Vienna and Zurich) were in line with figures reported for the cities (Raser et al., 2018). While trip distances were derived from Google API data, trip durations were self-reported. Trip durations from self-completion travel diaries are known to be overreported (Kelly et al., 2013), so mean speeds may have been lower than actual speeds leading to increased emissions rates in urban areas. However, further investigation of mean speeds by mode of transport showed that the derived mean speeds of $4.8 \mathrm{kph}$ for walking, $15.6 \mathrm{kph}$ for cycling/e-biking, $39.9 \mathrm{kph}$ for driving a car or van, and $17.9 \mathrm{kph}$ for urban public transport were in line with figures reported elsewhere (Raser et al., 2018). Note these are daily averages not just peak-time speeds (as often reported).

Third, outcome and exposure variables were reported at different time points and days of the week - this was taken into account in the mixed effect models by including 'day of the week' and person ID as random (intercept) variables. Other periodic effects cannot be excluded and we tried to cover for that as much as possible by including relevant time-varying covariates (such as participant age) and factors influencing outcomes such as ambient temperature (for 'cold start' emissions).

Fourth, our analysis is cross-sectional, meaning that the direction of causality (if any) behind many of the observed associations is unclear. A longitudinal analysis of change in emissions by change in exposures has been completed and published in Brand et al. (2021).

Fifth, while we accounted for several influencing factors that were often not available in previous studies, such as trip data by mode and purpose, accessibility and health status, our regression models did not account for more than $78 \%$ of the variation in the population (see Supplementary results). This suggests that travel choices and associated $\mathrm{CO}_{2}$ emissions are also influenced by other factors such as other built environment factors or lifestyle and socio-cultural factors (Brand et al., 2019; Panter et al., 2013; Weber and Perrels, 2000). We initially explored and added more 'objective', GIS based data at both home and work locations to the analysis, including street density, building density, richness of facilities, home-work distance, and public transport availability (timetables, frequency) (Gascon et al., 2019). However, none of these factors improved the models significantly, and the main findings were unchanged.

Sixth, we excluded carbon emissions from dietary intake as the evidence is not strong on whether day-to-day active travel (as opposed to performance/sport activity) significantly increases overall dietary intake when compared to motorized travel (Tainio et al., 2017).

Finally, the interdisciplinary breadth of the PASTA study meant that we measured daily travel behavior, individual and spatialenvironmental characteristics using briefer survey tools than might have been feasible in a single-discipline study. This may have introduced some measurement error that could have attenuated our effect sizes. However, the multi-city approach in different countries with different travel patterns, built environments, public transport accessibility levels and active mobility use adds value to the analysis, which clearly showed additional insights compared to smaller, single-location studies.

\section{Conclusions}

This paper started on the premise that we still do not know very much about how much carbon from passenger transport is saved overall - by travelling actively. It investigated to what extent active travel is associated with lower mobility-related life cycle $\mathrm{CO}_{2}$ emissions by using primary data collected in a large European multicentre study to derive total and purpose-specific life cycle $\mathrm{CO}_{2}$ emissions from travel activity at the individual and population levels. The analysis of a sample of thousands of participants and nearly 10,000 person-days of daily travel across the seven sites provided quantitative estimates of the life cycle carbon benefits of active travel using a variety of metrics that could be used in other European cities and beyond.

Active travel has attributes of social distancing that are likely to be desirable for some time (Kissler et al., 2020). It could help to cut 
back transportation energy use, $\mathrm{CO}_{2}$ emissions and air pollution while improving population health (Nieuwenhuijsen, 2020; Shaw et al., 2014) as confinement is eased. Therefore, locking in, investing in and promoting active travel should be a cornerstone of sustainability strategies, policies and planning (Andor et al., 2020; Creutzig et al., 2016; Creutzig et al., 2020) to meet our very challenging sustainable development goals that are unlikely to be met without significant mode shift to sustainable transport (Creutzig et al., 2018).

\section{CRediT authorship contribution statement}

Christian Brand: Conceptualization, Methodology, Data curation, Validation, Formal analysis, Writing - original draft, Writing review \& editing, Funding acquisition, Investigation, Visualization, Supervision, Project administration. Evi Dons: Conceptualization, Data curation, Formal analysis, Writing - review \& editing. Esther Anaya-Boig: Data curation, Writing - review \& editing. Ione AvilaPalencia: Data curation, Writing - review \& editing. Anna Clark: Data curation, Writing - review \& editing. Audrey Nazelle: Methodology, Writing - review \& editing, Funding acquisition, Investigation. Mireia Gascon: Data curation, Writing - review \& editing. Mailin Gaupp-Berghausen: Data curation, Writing - review \& editing. Regine Gerike: Methodology, Writing - review \& editing, Funding acquisition, Investigation. Thomas Götschi: Conceptualization, Data curation, Writing - review \& editing, Funding acquisition, Investigation. Francesco Iacorossi: Data curation, Writing - review \& editing. Sonja Kahlmeier: Data curation, Writing review \& editing, Funding acquisition, Investigation. Michelle Laeremans: Data curation, Writing - review \& editing. Mark $\mathbf{J}$ Nieuwenhuijsen: Conceptualization, Methodology, Writing - review \& editing, Funding acquisition, Investigation. Juan Pablo Orjuela: Data curation, Writing - review \& editing. Francesca Racioppi: Methodology, Writing - review \& editing, Funding acquisition, Investigation. Elisabeth Raser: Conceptualization, Methodology, Writing - review \& editing, Funding acquisition, Investigation. David Rojas-Rueda: Methodology, Data curation, Writing - review \& editing. Arnout Standaert: Data curation, Writing - review \& editing. Erik Stigell: Writing - review \& editing. Simona Sulikova: Methodology, Data curation, Writing - review \& editing. Sandra Wegener: Methodology, Writing - review \& editing. Luc Int Panis: Methodology, Data curation, Writing - review \& editing, Funding acquisition, Investigation.

\section{Declaration of Competing Interest}

The authors declare that they have no known competing financial interests or personal relationships that could have appeared to influence the work reported in this paper. The authors alone are responsible for the views expressed in this article and they do not necessarily represent the views, decisions or policies of the institutions with which they are affiliated.

\section{Acknowledgements}

This work was supported by the European project Physical Activity through Sustainable Transportation Approaches (PASTA). PASTA (http://www.pastaproject.eu/) was a four-year project funded by the European Union's Seventh Framework Program (EU FP7) under European Commission - Grant Agreement No. 602624. CB is also supported by UK Research and Innovation (UKRI) under the Centre for Research on Energy Demand Solutions (CREDS, Grant agreement number EP/R035288/1). ED is also supported by a postdoctoral scholarship from FWO - Research Foundation Flanders. ML held a joint PASTA/VITO PhD scholarship. SS is supported by the Martin Filko Scholarship from the Ministry of Education in Slovakia.

\section{Appendix A. Supplementary material}

Supplementary data to this article can be found online at https://doi.org/10.1016/j.trd.2021.102764.

\section{References}

ACEA/ANFAC, 2014. European Motor Vehicle Parc 2014: Vehicles in Use (2009-2014). ANFAC/ACEA, Madrid.

Adams, J., 2010. Prevalence and socio-demographic correlates of "active transport" in the UK: analysis of the UK time use survey 2005. Prev. Med. 50 (4), 199-203. Adra, N., Michaux, J.-L., Andre, M., 2004. Analysis of the load factor and the empty running rate for road transport. Artemis - assessment and reliability of transport emission models and inventory systems, ARTEMIS - Assessment and reliability of transport emission models and inventory systems, Report INRETS-LTE 0419 INRETS, Bron, FR.

Alvanides, S., 2014. Active transport: why and where do people (not) walk or cycle? J. Transport Health 1 (4), $211-213$.

Anable, J., Brand, C., 2019. Energy, pollution and climate change. In: Docherty, I., Shaw, J. (Eds.), Transport Matters. Policy Press, Bristol, p. 452.

Andor, M.A., Gerster, A., Gillingham, K.T., Horvath, M., 2020. Running a car costs much more than people think - stalling the uptake of green travel. Nature 580, 453-455.

Baltagi, B.H., 2008. Econometric Analysis of Panel Data, fourth ed. Wiley, New York.

Banister, D., 2008. The sustainable mobility paradigm. Transp. Policy 15 (2), 73-80.

Banister, D., 2018. Inequality in Transport. Alexandrine Press, Marcham, UK.

Banister, D., Watson, S., Wood, C., 1997. Sustainable cities, transport, energy and urban form. Environ. Plan. B: Plan. Des. 24 (1), $125-143$.

Bearman, N., Singleton, A.D., 2014. Modelling the potential impact on CO2 emissions of an increased uptake of active travel for the home to school commute using individual level data. J. Transport Health 1 (4), 295-304. 
Beckx, C., Broekx, S., Degraeuwe, B., Beusen, B., Int Panis, L., 2013. Limits to active transport substitution of short car trips. Transp. Res.: Part D: Transport Environ. 22, 10-13.

Beckx, C., Panis, L.I., Janssens, D., Wets, G., 2010. Applying activity-travel data for the assessment of vehicle exhaust emissions: application of a GPS-enhanced data collection tool. Transp. Res.: Part D: Transport Environ. 15 (2), 117-122.

Beenackers, M.A., Foster, S., Kamphuis, C.B., Titze, S., Divitini, M., Knuiman, M., van Lenthe, F.J., Giles-Corti, B., 2012. Taking up cycling after residential relocation: built environment factors. Am. J. Prev. Med. 42 (6), 610-615.

BEIS, 2019. Greenhouse gas reporting: conversion factors 2019, accessed at https://www.gov.uk/government/publications/greenhouse-gas-reporting-conversionfactors-2019 on 12 Nov 2019. Department for Business, Energy \& Industrial Strategy, London.

Bel, G., Rosell, J., 2017. The impact of socioeconomic characteristics on CO2 emissions associated with urban mobility: inequality across individuals. Energy Econ. 64, $251-261$.

Brand, C., 2008. Personal Travel and Climate Change - Exploring Climate Change Emissions from Personal Travel Activity of Individuals and Households, first ed. Verlag Dr. Müller (VDM), Saarbrücken.

Brand, C., Anable, J., Morton, C., 2019. Lifestyle, efficiency and limits: modelling transport energy and emissions using a socio-technical approach. Energ. Effi. 12 (1), 187-207.

Brand, C., Boardman, B., 2008. Taming of the few - The unequal distribution of greenhouse gas emissions from personal travel in the UK. Energy Policy 36 (1), 224-238.

Brand, C., Goodman, A., Ogilvie, D., 2014. Evaluating the impacts of new walking and cycling infrastructure on carbon dioxide emissions from motorized travel: a controlled longitudinal study. Appl. Energy 128, 284-295.

Brand, C., Goodman, A., Rutter, H., Song, Y., Ogilvie, D., 2013. Associations of individual, household and environmental characteristics with carbon dioxide emissions from motorised passenger travel. Appl. Energy 104, 158-169.

Brand, C., Götschi, T., Dons, E., Gerike, R., Anaya-Boig, E., Avila-Palencia, I., de Nazelle, A., Gascon, M., Gaupp-Berghausen, M., Iacorossi, F., Kahlmeier, S., Int Panis, L., Racioppi, F., Rojas-Rueda, D., Standaert, A., Stigell, E., Sulikova, S., Wegener, S., Nieuwenhuijsen, M.J., 2021. The climate change mitigation impacts of active travel: evidence from a longitudinal panel study in seven European cities. Global Environ. Change.

Brand, C., Preston, J.M., 2010. '60-20 emission'-The unequal distribution of greenhouse gas emissions from personal, non-business travel in the UK. Transp. Policy 17 (1), 9-19.

Branion-Calles, M., Winters, M., Nelson, T., de Nazelle, A., Panis, L.I., Avila-Palencia, I., Anaya-Boig, E., Rojas-Rueda, D., Dons, E., Götschi, T., 2019. Impacts of study design on sample size, participation bias, and outcome measurement: a case study from bicycling research. J. Transport Health 15 , 100651.

Brög, W., Erl, E., Ker, I., Ryle, J., Wall, R., 2009. Evaluation of voluntary travel behaviour change: experiences from three continents. Transp. Policy 16 (6), $281-292$.

Bryk, S.W., Raudenbush, A.S., 2002. Hierarchical Linear Models: Applications and Data Analysis Methods, second ed. Sage Publications, Thousand Oaks, CA.

Büchs, M., Schnepf, S.V., 2013. Who emits most? Associations between socio-economic factors and UK households' home energy, transport, indirect and total CO2 emissions. Ecol. Econ. 90, 114-123.

Buehler, R., 2011. Determinants of transport mode choice: a comparison of Germany and the USA. J. Transp. Geogr. 19 (4), $644-657$.

Cameron, I., Kenworthy, J.R., Lyons, T.J., 2003. Understanding and predicting private motorised urban mobility. Transp. Res.: Part D: Transport Environ. 8 (4), $267-283$.

Carlsson-Kanyama, A., Linden, A.-L., 1999. Travel patterns and environmental effects now and in the future: implications of differences in energy consumption among socio-economic groups. Ecol. Econ. 30 (3), 405-417.

Carse, A., Goodman, A., Mackett, R.L., Panter, J., Ogilvie, D., 2013. The factors influencing car use in a cycle-friendly city: the case of Cambridge. J. Transp. Geogr. 28, 67-74.

Castro, A., Gaupp-Berhausen, M., Dons, E., Standaert, A., Laeremans, M., Clark, A., Anaya, E., Cole-Hunter, T., Avila-Palencia, I., Rojas-Rueda, D., Nieuwenhuijsen, M., Gerike, R., Panis, L.I., de Nazelle, A., Brand, C., Raser, E., Kahlmeier, S., Götschi, T., 2019. Physical activity of electric bicycle users compared to conventional bicycle users and non-cyclists: Insights based on health and transport data from an online survey in seven European cities. Transp. Res. Interdis. Perspect. 100017.

Clark, B., Chatterjee, K., Melia, S., 2016. Changes to commute mode: The role of life events, spatial context and environmental attitude. Transp. Res.: Part A: Pol. Pract. 89, 89-105.

Creutzig, F., Agoston, P., Minx, J.C., Canadell, J.G., Andrew, R.M., Quéré, C.L., Peters, G.P., Sharifi, A., Yamagata, Y., Dhakal, S., 2016. Urban infrastructure choices structure climate solutions. Nat. Clim. Change 6 (12), 1054-1056.

Creutzig, F., Javaid, A., Koch, N., Knopf, B., Mattioli, G., Edenhofer, O., 2020. Adjust urban and rural road pricing for fair mobility. Nat. Clim. Change.

Creutzig, F., Roy, J., Lamb, W.F., Azevedo, I.M.L., Bruine de Bruin, W., Dalkmann, H., Edelenbosch, O.Y., Geels, F.W., Grubler, A., Hepburn, C., Hertwich, E.G., Khosla, R., Mattauch, L., Minx, J.C., Ramakrishnan, A., Rao, N.D., Steinberger, J.K., Tavoni, M., Ürge-Vorsatz, D., Weber, E.U., 2018. Towards demand-side solutions for mitigating climate change. Nat. Clim. Change 8 (4), 268-271.

Cuenot, F., Fulton, L., Staub, J., 2012. The prospect for modal shifts in passenger transport worldwide and impacts on energy use and CO2. Energy Policy 41, 98-106. Curtis, C., 1996. Can strategic planning contribute to a reduction in car-based travel? Transp. Policy 3 (1-2), 55-65.

de Nazelle, A., Morton, B.J., Jerrett, M., Crawford-Brown, D., 2010. Short trips: an opportunity for reducing mobile-source emissions? Transp. Res.: Part D: Transport Environ. 15 (8), 451-457.

DEFRA/DECC, 2016. UK Government conversion factors for Company Reporting, full 2016 dataset. Department for the Environment, Food and Rural Affairs and Department for Energy and Climate Change, London.

DfT, 2015. Transport Statistics Great Britain: 2015 Edition. Department for Transport, London.

Dons, E., Gotschi, T., Nieuwenhuijsen, M., de Nazelle, A., Anaya, E., Avila-Palencia, I., Brand, C., Cole-Hunter, T., Gaupp-Berghausen, M., Kahlmeier, S., Laeremans, M., Mueller, N., Orjuela, J.P., Raser, E., Rojas-Rueda, D., Standaert, A., Stigell, E., Uhlmann, T., Gerike, R., Int Panis, L., 2015. Physical Activity through Sustainable Transport Approaches (PASTA): protocol for a multi-centre, longitudinal study. BMC Public Health 15 (1), 1126.

Dons, E., Rojas-Rueda, D., Anaya-Boig, E., Avila-Palencia, I., Brand, C., Cole-Hunter, T., de Nazelle, A., Eriksson, U., Gaupp-Berghausen, M., Gerike, R., Kahlmeier, S., Laeremans, M., Mueller, N., Nawrot, T., Nieuwenhuijsen, M.J., Orjuela, J.P., Racioppi, F., Raser, E., Standaert, A., Int Panis, L., Götschi, T., 2018. Transport mode choice and body mass index: cross-sectional and longitudinal evidence from a European-wide study. Environ. Int. 119, $109-116$.

ECF, 2011. Cycle more Often 2 cool down the planet! - Quantifying CO2 savings of Cycling. European Cyclists' Federation (ECF), Brussels.

Ecometrica, 2011. Electricity-specific emission factors for grid electricity. Ecometrica.

EEA, 2012. COPERT 4 (COmputer Programme to calculate Emissions from Road Transport), last accessed at http://emisia.com/content/copert-documentation on 20/ 02/2018. European Environment Agency, Copenhagen.

EEA, 2016. Carbon dioxide emissions from passenger transport, TERM 027 indicator and TRACCS database. European Environment Agency, Copenhagen.

EEA, 2019. Total greenhouse gas emission trends and projections in Europe, accessed at https://www.eea.europa.eu/data-and-maps/indicators/greenhouse-gasemission-trends-6/assessment-3 on 30/03/2020. European Environment Agency, Copenhagen.

EMEP/EEA, 2016. EMEP/EEA air pollutant emission inventory guidebook 2016, Technical guidance to prepare national emission inventories. European Environment Agency, Copenhagen.

EPOMM, 2020. TEMS - The EPOMM Modal Split Tool, accessed at http://www.epomm.eu/tems/index.phtml on 21/3/2020. European Platform on Mobility Management (EPOMM), Leuven, BE.

Eurostat, 2016. Transport data database, October 2015 update. Last accessed at http://ec.europa.eu/eurostat/web/transport/data/database on 10/03/2017. Eurostat, European Commission, Brussels.

Eurostat, 2020. Energy, transport and environment statistics: 2020 edition, accessed at https://ec.europa.eu/eurostat/documents/3217494/11478276/KS-DK-20001-EN-N.pdf/06ddaf8d-1745-76b5-838e-013524781340 Eurostat, European Union, Brussels. 
Frank, L.D., Greenwald, M.J., Winkelman, S., Chapman, J., Kavage, S., 2010. Carbonless footprints: promoting health and climate stabilization through active transportation. Prev. Med. 50 (Suppl 1), S99-S105.

Gascon, M., Götschi, T., Nazelle, A.d., Gracia, E., Ambròs, A., Márquez, S., Marquet, O., Avila-Palencia, I., Brand, C., Iacorossi, F., Raser, E., Gaupp-Berghausen, M., Dons, E., Laeremans, M., Kahlmeier, S., Sánchez, J., Gerike, R., Anaya-Boig, E., Panis, L.I., Nieuwenhuijsen, M., 2019. Correlates of Walking for Travel in Seven European Cities: The PASTA Project. Environ. Health Perspect. 127(9), 097003.

Gaupp-Berghausen, M., Raser, E., Anaya-Boig, E., Avila-Palencia, I., de Nazelle, A., Dons, E., Franzen, H., Gerike, R., Götschi, T., Iacorossi, F., Hössinger, R., Nieuwenhuijsen, M., Rojas-Rueda, D., Sanchez, J., Smeds, E., Deforth, M., Standaert, A., Stigell, E., Cole-Hunter, T., Int Panis, L., 2019. Evaluation of different recruitment methods: longitudinal, web-based, pan-European physical activity through sustainable transport approaches (PASTA) project. J. Med. Internet Res. 21 (5), e11492.

Gerike, R., de Nazelle, A., Nieuwenhuijsen, M., Panis, L.I., Anaya, E., Avila-Palencia, I., Boschetti, F., Brand, C., Cole-Hunter, T., Dons, E., Eriksson, U., GauppBerghausen, M., Kahlmeier, S., Laeremans, M., Mueller, N., Orjuela, J.P., Racioppi, F., Raser, E., Rojas-Rueda, D., Schweizer, C., Standaert, A., Uhlmann, T., Wegener, S., Götschi, T., 2016. Physical Activity through Sustainable Transport Approaches (PASTA): a study protocol for a multicentre project. BMJ Open 6 (1), e009924.

Goodman, A., Brand, C., Ogilvie, D., 2012. Associations of health, physical activity and weight status with motorised travel and transport carbon dioxide emissions: a cross-sectional, observational study. Environ. Health 11 (1), 52.

Goodman, A., Rojas, I.F., Woodcock, J., Aldred, R., Berkoff, N., Morgan, M., Abbas, A., Lovelace, R., 2019. Scenarios of cycling to school in England, and associated health and carbon impacts: application of the 'Propensity to Cycle Tool'. J. Transport Health 12, $263-278$.

Goodman, A., Sahlqvist, S., Ogilvie, D., 2014. New walking and cycling routes and increased physical activity: one- and 2-year findings from the UK iConnect study. Am. J. Public Health e1-e9.

Gössling, S., Choi, A., Dekker, K., Metzler, D., 2019. The social cost of automobility, cycling and walking in the European Union. Ecol. Econ. 158, 65-74.

Götschi, T., de Nazelle, A., Brand, C., Gerike, R., 2017. Towards a comprehensive conceptual framework of active travel behavior: a review and synthesis of published frameworks. Curr. Environ. Health Rep. 4 (3), 286-295.

Götschi, T., Kahlmeier, S., Castro, A., Brand, C., Cavill, N., Kelly, P., Lieb, C., Rojas-Rueda, D., Woodcock, J., Racioppi, F., 2020. Integrated impact assessment of active travel: expanding the scope of the health economic assessment tool (HEAT) for walking and cycling. Int. J. Environ. Res. Public. Health 17 (20).

Graham-Rowe, E., Skippon, S., Gardner, B., Abraham, C., 2011. Can we reduce car use and if so, how? A review of available evidence. Transp. Res.: Part A: Pol. Practice 45 (5), 401-418.

ICCT, 2017. Road tested: Comparative overview of real-world versus type-approval NOX and CO2 emissions from diesel cars in Europe, ICCT White Paper. Last accessed at https://www.theicct.org/sites/default/files/publications/ICCT_RoadTested_201709.pdf on 18/04/2018. International Council on Clean Transportation, Berlin.

IEA, 2015. World energy outlook 2015. International Energy Agency (IEA), Paris.

IIASA, 2014. IIASA GAINS model, scenario WPE_2014_CLE: the updated 'current legislation' (after the bilateral consultations in 2014) of the PRIMES 2013 REFERENCE activity projection. IIASA, Laxenburg, Austria.

IPCC, 2018. Global Warming of $1.5^{\circ} \mathrm{C}$, Special Report. Last accessed in October 2018 at: http://www.ipcc.ch/report/sr15/. Intergovernmental Panel on Climate Change, Geneva.

Javaid, A., Creutzig, F., Bamberg, S., 2020. Determinants of low-carbon transport mode adoption: systematic review of reviews. Environ. Res. Lett. 15 (10), 103002.

JEC, 2014. JEC Well-To-Wheels Analysis, Report EUR 26237 EN - 2014. Last accessed at http://iet.jrc.ec.europa.eu/about-jec/sites/iet.jrc.ec.europa.eu.about-jec/ files/documents/report_2014/wtt_report_v4a.pdf on 10/03/2017. JEC - Joint Research Centre-EUCAR-CONCAWE collaboration, Brussels.

JRC, 2013. Analysis of National Travel Statistics in Europe. European Commission, Joint Research Centre. ISBN: 978-92-79-32358-4, Seville.

Keall, M.D., Shaw, C., Chapman, R., Howden-Chapman, P., 2018. Reductions in carbon dioxide emissions from an intervention to promote cycling and walking: a case study from New Zealand. Transp. Res.: Part D: Transport Environ. 65, 687-696.

Kelly, P., Krenn, P., Titze, S., Stopher, P., Foster, C., 2013. Quantifying the difference between self-reported and global positioning systems-measured journey durations: a systematic review. Transport Rev. 33 (4), 443-459.

Kissler, S.M., Tedijanto, C., Goldstein, E., Grad, Y.H., Lipsitch, M., 2020. Projecting the transmission dynamics of SARS-CoV-2 through the postpandemic period. Science 368 (6493), 860.

Ko, J., Park, D., Lim, H., Hwang, I.C., 2011. Who produces the most CO2 emissions for trips in the Seoul metropolis area? Transp. Res.: Part D: Transport Environ. 16 (5), 358-364.

Lovelace, R., Beck, S.B.M., Watson, M., Wild, A., 2011. Assessing the energy implications of replacing car trips with bicycle trips in Sheffield, UK. Energy Policy 39 (4), 2075-2087.

Neves, A., Brand, C., 2019. Assessing the potential for carbon emissions savings from replacing short car trips with walking and cycling using a mixed GPS-travel diary approach. Transp. Res.: Part A: Pol. Pract. 123, 130-146.

Nicolas, J.-P., David, D., 2009. Passenger transport and CO2 emissions: what does the French transport survey tell us? Atmos. Environ. 43 (5), $1015-1020$.

Nieuwenhuijsen, M.J., 2020. Urban and transport planning pathways to carbon neutral, liveable and healthy cities; A review of the current evidence. Environ. Int. 105661 .

Odeh, N., Hill, N., Forster, D., 2013. Current and Future Lifecycle Emissions of Key "Low Carbon" Technologies and Alternatives, Final Report. Ricardo AEA for the Committee on Climate Change, Harwell, UK.

Panter, J., Corder, K., Griffin, S., Jones, A., van Sluijs, E., 2013. Individual, socio-cultural and environmental predictors of uptake and maintenance of active commuting in children: longitudinal results from the SPEEDY study. Int. J. Behav. Nutr. Phys. Act. 10 (1), 83.

Preston, I., White, V., Thumim, J., Bridgeman, T., Brand, C., 2013. Distribution of Carbon Emissions in the UK: Implications for Domestic Energy Policy. Joseph Rowntree Foundation, London.

Quarmby, S., Santos, G., Mathias, M., 2019. Air quality strategies and technologies: a rapid review of the international evidence. Sustainability 11 (10).

Rabl, A., de Nazelle, A., 2012. Benefits of shift from car to active transport. Transport Policy 19 (1), $121-131$.

Raser, E., Gaupp-Berghausen, M., Dons, E., Anaya-Boig, E., Avila-Palencia, I., Brand, C., Castro, A., Clark, A., Eriksson, U., Götschi, T., Int Panis, L., Kahlmeier, S., Laeremans, M., Mueller, N., Nieuwenhuijsen, M., Orjuela, J.P., Rojas-Rueda, D., Standaert, A., Stigell, E., Gerike, R., 2018. European cyclists' travel behavior: Differences and similarities between seven European (PASTA) cities. J. Transport Health 9, 244-252.

Rodrigues, P.F., Alvim-Ferraz, M.C.M., Martins, F.G., Saldiva, P., Sá, T.H., Sousa, S.I.V., 2020. Health economic assessment of a shift to active transport. Environ. Pollut. 258, 113745 .

Sælensminde, K., 2004. Cost-benefit analyses of walking and cycling track networks taking into account insecurity, health effects and external costs of motorized traffic. Transp. Res.: Part A: Pol. Pract. 38 (8), 593-606.

Scheepers, C.E., Wendel-Vos, G.C.W., den Broeder, J.M., van Kempen, E.E.M.M., van Wesemael, P.J.V., Schuit, A.J., 2014. Shifting from car to active transport: a systematic review of the effectiveness of interventions. Transp. Res.: Part A: Pol. Pract. 70, 264-280.

Shaw, C., Hales, S., Howden-Chapman, P., Edwards, R., 2014. Health co-benefits of climate change mitigation policies in the transport sector. Nat. Clim. Change 4 (6), $427-433$.

Sims, R., Schaeffer, R., Creutzig, F., Cruz-Núñez, X., D’Agosto, M., Dimitriu, D., Meza, M.J.F., Fulton, L., Kobayashi, S., O., L., McKinnon, A., Newman, P., Ouyang, M., Schauer, J.J., Sperling, D., Tiwari, G., 2014. Transport. In: Edenhofer, O., Pichs-Madruga, R., Sokona, Y., Farahani, E., Kadner, S., Seyboth, K., Adler, A., Baum, I., Brunner, S., Eickemeier, P., Kriemann, B., Savolainen, J., Schlömer, S., Stechow, C.v., Zwickel, T., Minx, J.C. (Eds.), Climate Change 2014: Mitigation of Climate Change. Contribution of Working Group III to the Fifth Assessment Report of the Intergovernmental Panel on Climate Change. Cambridge University Press, Cambridge, United Kingdom and New York, NY, USA.

SMMT, 2016. UK new car market starts 2016 on a high with best January in 11 years, http://www.smmt.co.uk/2016/02/uk-new-car-market-starts-2016-on-a-highwith-best-january-in-11-years/ [last accessed on 18/01/2016]. SMMT, London. 
Socialdata, 2009. The New KONTIV-Design (NKD), accessed at http://www.socialdata.de/info/KONTIV_engl.pdf on 8 September 2019 Socialdata GmbH, Munich. Stead, D., 1999. Relationships between transport emissions and travel patterns in Britain. Transp. Policy 6 (4), $247-258$.

Susilo, Y.O., Stead, D., 2009. Individual carbon dioxide emissions and potential for reduction in the Netherlands and the United Kingdom. Transp. Res. Rec. 2139, $142-152$.

Tainio, M., Monsivais, P., Jones, N.R., Brand, C., Woodcock, J., 2017. Mortality, greenhouse gas emissions and consumer cost impacts of combined diet and physical activity scenarios: a health impact assessment study. BMJ Open 7 (2).

Timmermans, H., van der Waerden, P., Alves, M., Polak, J., Ellis, S., Harvey, A.S., Kurose, S., Zandee, R., 2003. Spatial context and the complexity of daily travel patterns: an international comparison. J. Transp. Geogr. 11 (1), 37-46.

U.S. Department of Transportation, 2017. National Household Travel Survey: Vehicle Trips, accessed at https://nhts.ornl.gov/vehicle-trips on 20/03/2020. U.S. Department of Transportation, Federal Highway Administration, Washington, DC.

Vagane, L., 2007. Short car trips in Norway: is there a potential for modal shift? Proceedings of the European Transport Conference (ETC) 2007 held 17-19 October 2007, Leiden, The Netherlands.

VanderWeele, T.J., 2016. Mediation analysis: a practitioner's guide. Annu. Rev. Public Health 37 (1), 17-32.

Vittinghoff, E., Glidden, D.V., Shiboski, S.C., McCulloch, C.E., 2012. Regression Methods in Biostatistics: Linear, Logistic, Survival, and Repeated Measures Models, second ed. Springer, Boston, MA.

Wanner, M., Götschi, T., Martin-Diener, E., Kahlmeier, S., Martin, B.W., 2012. Active transport, physical activity, and body weight in adults. Am. J. Prev. Med. 42 (5), 493-502.

Weber, C., Perrels, A., 2000. Modelling lifestyle effects on energy demand and related emissions. Energy Policy 28 (8), 549-566.

Welch, T.F., 2013. Equity in transport: The distribution of transit access and connectivity among affordable housing units. Transp. Policy 30, $283-293$.

Woodcock, J., Abbas, A., Ullrich, A., Tainio, M., Lovelace, R., Sá, T.H., Westgate, K., Goodman, A., 2018. Development of the Impacts of Cycling Tool (ICT): A modelling study and web tool for evaluating health and environmental impacts of cycling uptake. PLoS Med. 15 (7), e1002622.

Woodcock, J., Edwards, P., Tonne, C., Armstrong, B.G., Ashiru, O., Banister, D., 2009. Public health benefits of strategies to reduce greenhouse-gas emissions: urban land transport. Lancet 374 .

Yang, Y., Wang, C., Liu, W., 2018. Urban daily travel carbon emissions accounting and mitigation potential analysis using surveyed individual data. J. Cleaner Prod. 192, 821-834. 